Sabrina Baroni

Estudos moleculares em Gymnotus pantherinus (Gymnotiformes, Gymnotidae): uma abordagem

Sistemática e Filogeográfica

Tese apresentada ao Instituto de Biociências da Universidade de São Paulo, para a obtenção de Título de Doutor em Ciências, na Área de Biologia/Genética.

Orientador(a): Prof ${ }^{\mathrm{a}}$ Dr$^{\mathrm{a}}$ Lurdes Foresti de Almeida-Toledo

São Paulo

2010 


\section{Baroni, Sabrina}

Estudos Moleculares em Gymnotus pantherinus (Gymnotiformes, Gymnotidae): uma abordagem Sistemática e Filogeográfica

$155 \mathrm{p}$.

Tese (Doutorado) - Instituto de Biociências da Universidade de São Paulo. Departamento de Genética e Biologia Evolutiva.

1. Gymnotus pantherinus 2. drenagens costeiras 3. Filogenia 4. Filogeografia 5. estrutura de populações.

I. Universidade de São Paulo. Instituto de Biociências. Departamento de Genética e Biologia Evolutiva.

Comissão Julgadora:

Prof. (a) Dr.(a)

Prof. (a) Dr.(a)
Prof. (a) Dr.(a)

Prof. (a) Dr.(a)

Profa Dr ${ }^{\mathrm{a}}$ Lurdes Foresti de Almeida-Toledo

Orientadora 
À minha amada família

Pedro, Geni, Ana, Mônica e Sofia, sempre! 
Precisamos dar um sentido humano às nossas construções.

E, quando o amor ao dinheiro, ao sucesso, nos estiver deixando cegos, saibamos fazer pausas para olhar os lírios do campo e as aves do céu.

(Érico Veríssimo) 


\section{Agradecimentos}

Deixo registrado aqui os meus mais sinceros agradecimentos a todos que, direta ou indiretamente, contribuíram para a realização deste trabalho. Foram muitas as pessoas que participaram ou colaboraram de alguma forma na execução deste, as quais sou muito grata, seja pelo apoio técnico e científico, ou ainda pelo incentivo, amizade e carinho, por vezes tão necessários! E desde já aviso que a lista é grande...

À Prof. ${ }^{a}$ Dr $^{\mathrm{a}}$ Lurdes Foresti de Almeida-Toledo, por tudo que resume nossos sete anos de convivência. Pelo acolhimento, pela disposição e orientação, mas sobretudo, pela confiança e pela oportunidade.

Aos professores do Departamento de Genética e Biologia Evolutiva e do Departamento de Zoologia, agora que minha vida passou a ser dividida por essas duas grandes áreas do conhecimento, agradeço pela minha formação científica, pela qualidade do programa de Pós-graduação da USP e pelos ensinamentos, tanto profissional quanto pessoal.

Em especial, agradeço ao Prof. Dr. Miguel Trefaut U. Rodrigues e Prof. Dr. Antônio Carlos Marques, meus chefes diretos no Departamento de Zoologia, principalmente pela compreensão com o meu estado de doutoranda. E ao Prof. Dr. Fernando Portella de Luna Marques por tantas coisas... desde a fase inicial de excecução do projeto, pela ajuda com o desenho experimental de primers, otimização das reações de amplificação e seqüenciamento, pela paciência com minhas discussões sobre os métodos de análises, disponibilização do cluster, enfim, do começo ao fim desse projeto sua ajuda foi inestimável.

Às secretárias do Departamento de Genética e Biologia Evolutiva, especialmente Deisy, Helenice e Neide, e do Departamento de Zoologia, Marly (santa Marly!), Fran, Maria Lúcia e Luzinéia, sempre prestativas e eficientes. Agradeço também aos 
funcionários da secretaria de Pós-graduação e da Biblioteca do Instituto de Biociências.

À Luci Navarro, responsável pelo serviço de seqüenciamento do Instituto de Química da USP, pela eficiência com que desempenha seu trabalho.

Ao Prof. Dr. Cláudio Oliveira, pela gentileza em fornecer amostras de tecidos de outros Gymnotus e de primers.

Aos amigos do Laboratório de Ictiogenética e Laboratório de Sistemática Molecular (e mais alguns avulsos inclusos nesse tópico): Felippe L. Claro, Riviane Garcez, Ricardo S. Hattori, Vânia Pretti, Claudia Olivares, Denis J. Machado e Bianca, Ezequiel Ale, J. Cassimiro da Silva, Juliana Bardi, Karin Fehlauer, Lucília Miranda, Maíra Concistré, Marco Sena, Maximiliano M. Maronna, Manuel Antunes-Jr, Nathalia Mejia e Julian Esteban, Renata Cecília Amaro, Silvia Geurgas, Antoine Fouquet, Roberta Figueiredo e Fernando Nodari, Jéssica Gillung, Marcus V. Domingues e Verônica M. Bueno, pela agradável convivência e por TODAS as experiências compartilhadas nesse período. Nossa amizade fez com que esse processo se tornasse algo mais leve.

Aos amigos “externos”, Janice M. da Cunha, Ilana Fichberg, Carine Chamon, Leandro M. Sousa, Katia Pellegrino, Bill, Tico Marcondes, simplesmente por vocês existirem e fazerem parte da minha vida!

Aos amigos da dança, porque a dança foi meu refúgio nos momentos de desespero, especialmente David e Carla, por aturarem as minha reclamações. E Paulão, parceiro do Zouk!

Às amigas queridas da "velha guarda" do LIUSP, Flora M.D.C. Fernandes, Maria de Fátima Z. D. Silva, Soraia B. A. Fonteles, Cinthia B. Moysés e Daniela Calcagnotto, pela amizade e inspiração. Só não agradeço pela saudade que vocês todas deixaram...

À todos os amigos que gentilmente me ajudam com a coleta dos Gymnotus: Antonio, Francisco, George, Janice, José Birindelli e, especialmente, Mauro Cardoso. Muito obrigada, não só pelos exemplares coletados, mas também pelos risos, ou pelas lágrimas (né, Maureba)! Meus agradecimentos se extendem também aos motoristas do 
Instituto de Biociências, Marcelo, Pena, Valmir e Valdir.

À amiga Patrícia Faria, você é realmente uma pessoa especial! Agradeço pela amizade e também pela impecável revisão dos textos.

Ao amigo Almir Pepato, por toda ajuda e paciência com minhas análises bayesianas.

À todos os companheiros da ReGeneC 2009, em especial aos professores Antonio M. Solé-Cava, Cristina Yumi Miyaki, Daniel Ruzzante, Elie Poulin, Marco Mendes e a doce Tina (María A. Oliveira), pela experiência incrível vivida durante o workshop. Grande parte desse trabalho é fruto das aulas e discussões ocorridas durante o encontro.

E, de modo especial, ao nosso mais do que técnico, Carlos Eduardo Lopes. Amigo de todas as horas, presente nas alegrias, mas também nos momentos de angústia ou de incertezas... Consultor de todos os assuntos, não só profissionais quanto pessoais, você é uma pessoa incrível. Parceiro nas picadas de vespas e maior coletor de Gymnotus do mundo. Não seria nem preciso dizer que sem você esse trabalho não teria sido concluído da forma que está, pois a amostragem de Gymnotus pantherinus que obtivemos é resultado do seu esforço e dedicação. Enfim, não há palavras para expressar o meu carinho e a minha admiração por você. E agradeço também a Marta Canovas, igualmente amiga e companheira, e mais do que isso, obrigada por "dividir" o Carlos com a gente!

Finalmente, agradeço à minha família, a quem eu devo minha educação e meu caráter. 


\section{Índice}

\section{Lista de Figuras}

\section{Lista de Tabelas}

Capítulo I - Introdução Geral............................................................. $\quad 1$

Capítulo II - Avaliação do status taxonômico de Gymnotus pantherinus, com base em marcadores moleculares mitocondriais e nucleares................................................................... 28

Capítulo III - Estudo dos padrões demográficos de Gymnotus pantherinus (Gymnotiformes, Gymnotidae): um modelo de diversificação da ictiofauna em drenagens costeiras do sudeste/sul brasileiro

Considerações Finais

Resumo e Abstract

Referências Bibliográficas

Anexos 


\section{Introdução Geral}

\section{A ordem Gymnotiformes e a família Gymnotidae}

Os peixes exibem uma enorme diversidade, tanto morfológica, como na exploração dos hábitats e, ainda, em sua biologia. Essa diversidade é, em parte, o que faz com que o entendimento da história evolutiva do grupo e o estabelecimento de uma classificação seja uma tarefa tão difícil (Nelson, 2006). Parte de toda essa diversidade está abrigada na região Neotropical, a qual mantém uma ictiofauna de água doce extremamente numerosa e diversificada, estimada em 4475 espécies válidas (Reis et al., 2003), embora esse número possa chegar a mais de 6000 quando consideradas as espécies ainda não descritas. A região Neotropical é marcada por histórias complexas de conexões e rupturas dos sistemas hidrológicos durante o tempo geológico, que geraram padrões igualmente complexos de distribuição da fauna e das relações entre os diversos táxons ocorrentes (Lundberg et al., 1998). Considerando-se a riqueza de espécies e a complexidade de seus padrões de distribuição, os conhecimentos sobre a diversidade genética e as relações filogenéticas entre as espécies neotropicais são ainda escassos.

A ordem Gymnotiformes é composta por um grupo monofilético de peixes endêmicos da região Neotropical, na qual são reconhecidas cinco famílias: Apteronotidae, Gymnotidae, Hypopomidae, Rhamphichthyidae e Sternopygidae (Albert \& Campos-da-Paz, 1998; Albert, 2001; Nelson, 2006). 
Revisões mais recentes reconhecem nessa ordem a existência de 30 gêneros e 134 espécies (Nelson, 2006), embora haja evidências de que muitas espécies ainda não estejam descritas, constituindo atualmente complexos de espécies (e.g., Moysés, 2005; Gonçalves, 2005; Milhomem et al., 2008; Nagamachi et al., 2010). Apesar da ampla distribuição geográfica da ordem, que se estende desde o rio Salado (La Plata) na Argentina, até o rio San Nicolas, em Chiapas, sul do México (Mago-Leccia, 1994), da costa do Pacífico à costa Atlântica (figura 1.1), é na região Amazônica que se concentra a maior diversidade de espécies de Gymnotiformes (Mago-Leccia, 1994; Lundberg et al., 1996; Fernandes et al., $2004)$.

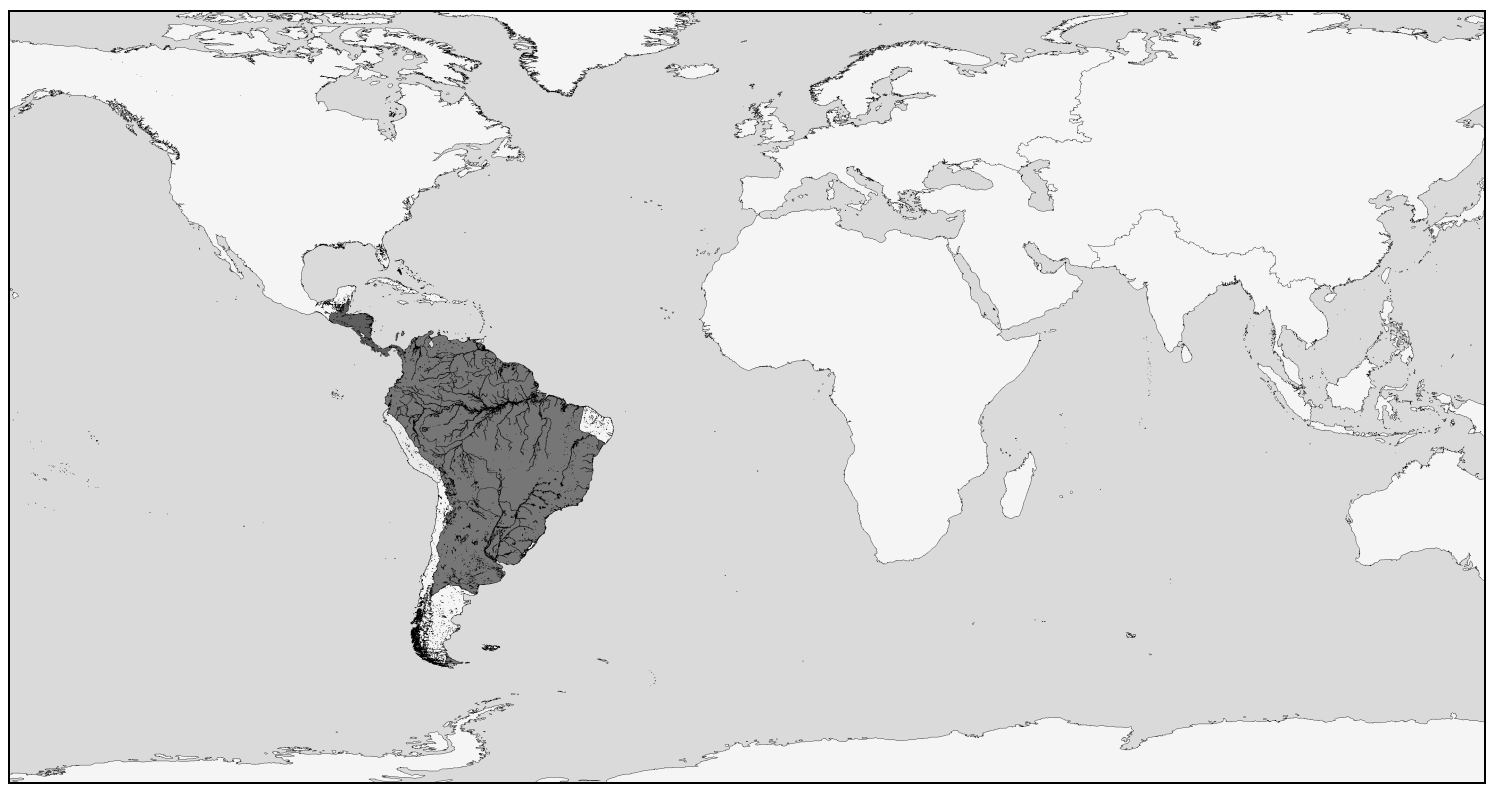

Figura 1.1 - Mapa da distribuição geográfica da Ordem Gymnotiformes, destacada em cinza.

Os Gymnotiformes se destacam em relação aos outros peixes neotropicais por apresentarem uma morfologia bastante distinta: possuem o corpo alongado 
e lateralmente comprimido, com ausência das nadadeiras dorsal e pélvica; nadadeira caudal reduzida ou completamente ausente e nadadeira anal, bastante alongada (figura 1.2), responsável pela locomoção dos organismos através de movimentos ondulatórios, que permitem que os indivíduos se desloquem para frente e para trás (Mago-Lecia, 1994).

São peixes que possuem uma grande capacidade de regeneração dos tecidos e essa capacidade biológica pode por vezes dificultar a identificação taxonômica dos indivíduos, porque as cicatrizes formadas pelo processo de regenação alteram de certa forma a morfologia do animal, principalmente a região posterior do corpo, muito utilizada para a taxonomia. De hábitos noturnos, permanecem escondidos durante o dia em fendas, rachaduras ou outros locais protegidos. Alimentam-se preferencialmente de insetos aquáticos (particularmente Chironomidae) e pequenos crustáceos, embora espécies maiores, como Eletrophorus electricus e algumas espécies de Sternopygus, sejam também piscívoras.

Outra característica biológica marcante do grupo é a bioeletricidade. Todas as espécies de Gymnotiformes são capazes de emitir e detectar sinais elétricos fracos por meio de órgãos eletrogênicos e eletrorreceptores formados por vários tipos de células sensoriais especializadas denominadas eletrócitos (Shaffer, 1917; Lissmann, 1958). A atividade elétrica permite a comunicação, localização, forrageamento e a orientação em relação ao substrato à noite e no escuro, ou ainda em águas barrentas, o que contribui para o sucesso do grupo nos ecossistemas aquáticos Neotropicais (Crampton \& Albert, 2006). As descargas elétricas produzidas pelos indivíduos são fracas, da ordem de milivolts, com exceção apenas da espécie Eletrophorus electricus (o popular 
poraquê), capaz de produzir descargas elétricas fortes, da ordem de 500/600 V (Hopkins, 2009).

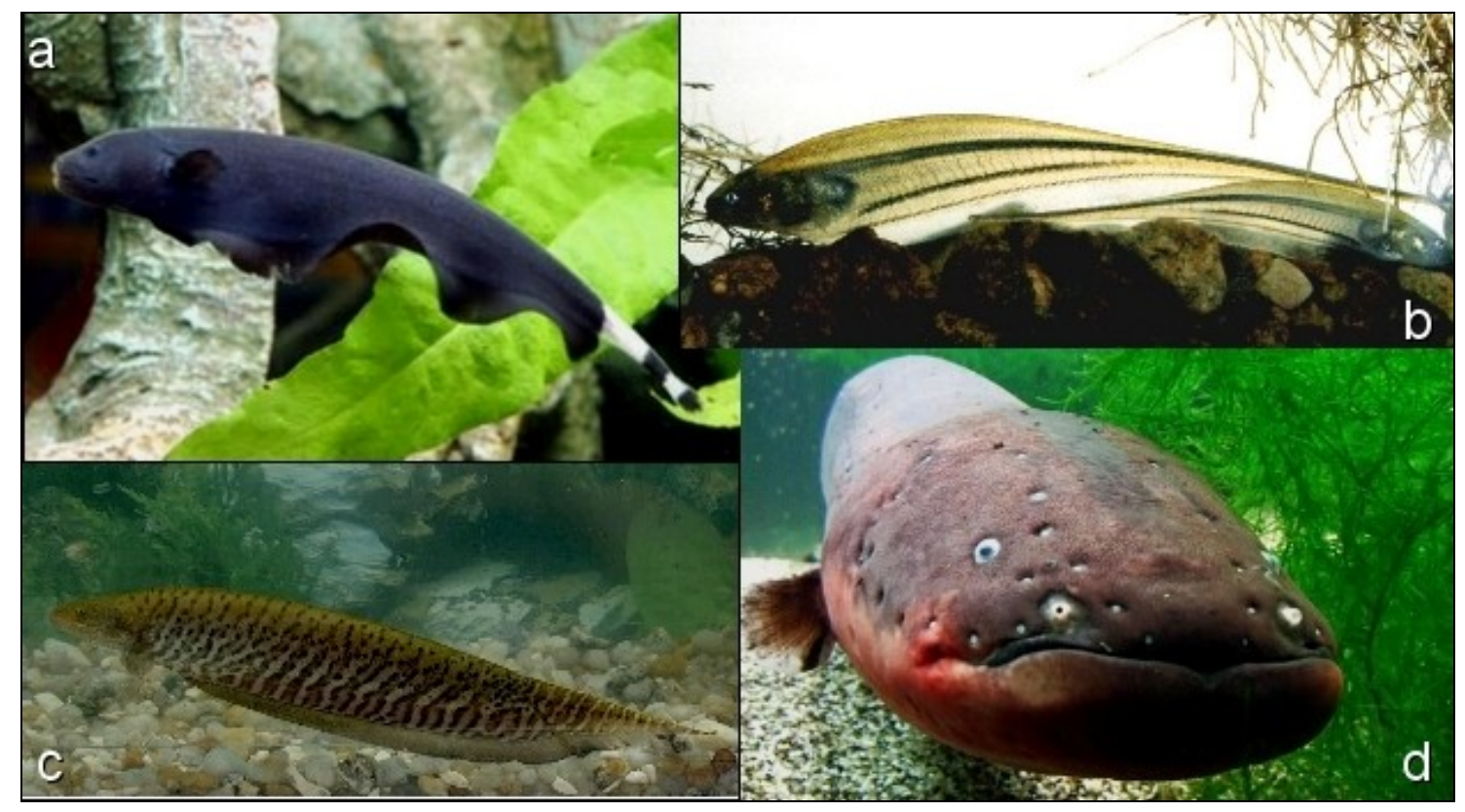

Figura 1.2 - Exemplos da diversidade morfológica do grupo: (a) Apteronotus albifrons*; (b) Eigenmannia virescens (Fonte: Fishbase); (c) Gymnotus sylvius; (d) Electrophorus electricus*. *Fotos obtidas da internet, autor desconhecido.

O primeiro registro fóssil de Gymnotiformes foi feito por geólogos petroleiros em depósitos aluviais do Alto Rio Moile, Bacia do Paraná, em uma floresta localizada cerca de $75 \mathrm{~km}$ a noroeste de Santa Cruz, na Bolívia (Gayet \& Meunier, 1991; Albert \& Fink, 2007). Exemplares incompletos foram encontrados na Formação Yecua, datata do Mioceno Superior, com aproximadamente 10 milhões de anos (Ma), constituindo a drenagem protoParaná. A dificuldade de atribuição a um táxon preciso fez com que os 
espécimes fossem alocados em um novo táxon, nomeado como Ellisella kirschbaumi por Gayet \& Meunier (1991), em homenagem a Max Ellis e Frank Kirschbaumi, os pioneiros nos estudos dos processos de crescimento e regeneração em Gymnotiformes. O gênero foi substituído subseqüentemente por Humboldichthys, uma vez que o nome Ellisella fora previamente atribuído a um celenterado (Gray, 1858) e a um gastrópode (Rohr \& Huddleston, 1982) (Albert \& Fink, 2007).

Albert \& Fink (2007), investigando a posição filogenética dos fósseis, hipotetizaram que o holótipo $H$. kirschbaumi seria grupo irmão do gênero Sternopygus. O holótipo compartilha o opérculo estriado com espécies ainda existentes de Sternopygus e Distocyclus, e pode ser atribuído à família Sternopygidae, embora suas estrias sejam significantemente mais pronunciadas do que as estrias das espécies atuais. Incertezas acerca do posicionamento desses exemplares fósseis irão persistir até que um número maior de espécimes seja coletado (Albert \& Fink, 2007). Ainda assim, o achado fóssil indica que a origem dos Gymnotiformes é relativamente recente, o que torna esse grupo de peixes especialmente interessante em estudos evolutivos e geológicos da América Latina, uma vez que, possivelmente, tenham se originado após a separação da Gondwana (Fernandes-Matioli, 1999).

Dentre os Gymnotiformes, a família Gymnotidae compreende espécies com a maior distribuição geográfica dentro da região Neotropical (Mago-Lecia, 1994). Durante muito tempo, Gymnotidae foi considerada uma família monotípica, contemplando apenas o gênero Gymnotus. Com a revisão sistemática e taxonômica realizada em 1998 por Albert e Campos-da-Paz, foi proposta a inclusão do gênero Eletrophorus nessa família, já que a similaridade 
entre esses dois gêneros já fora noticiada por vários autores (Campos-da-Paz, 2003). Sendo assim, a família Gymnotidae atualmente inclui o gênero Eletrophorus, monoespecífico (E. eletricus) e o gênero Gymnotus, que conta atualmente com 35 espécies reconhecidas (Froese \& Pauly, 2010) (anexo 1), e representa o gênero mais diverso dentro de Gymnotiformes, embora provavelmente existam muitas espécies ainda não descritas. Estudos recentes demonstram que a diversidade do gênero é bem maior do que a previamente reconhecida, em parte devido a limitações nos métodos de coleta e acesso aos hábitats (Gonçalves, 2005). Novos esforços de coletas e identificação, associados a caracterização das descargas elétricas e a estudos genéticos elevaram em muito o número de espécies descritas nos últimos anos (Albert \& Crampton, 2003). Assim como a Ordem Gymnotiformes, a maior diversidade do gênero Gymnotus também ocorre na bacia Amazônica, onde são reconhecidas 18 espécies (Crampton et al., 2005).

Albert et al. (2005) analisaram as relações filogenéticas do gênero Gymnotus com base em caracteres morfológicos. Os resultados obtidos corroboraram as hipóteses prévias acerca das relações intragenéricas, com o reconhecimento de três grupos principais: o grupo G. cylindricus representado por duas espécies da região central da América Central; o grupo G. pantherinus formado por 13 espécies com distribuição do Panamá ao Paraguai; e, o grupo G. carapo, composto por 16 espécies que se distribuem da encosta do Pacífico, na Colômbia, aos Pampas argentinos. O primeiro grupo apresenta-se basal em relação aos outros dois grupos da América do Sul, e espécies das encostas Pacífica e Atlântica dos Andes são encontradas dentro dos dois outros clados (grupo G. pantherinus e grupo G. carapo). Em estudo subseqüente, Lovejoy et 
al. (2010) reanalisaram a filogenia do gênero, incorporando às matrizes morfológicas, dados moleculares obtidos a partir das seqüências gênicas: 16S, Citocromo b e RAG2. Os resultados obtidos nesse estudo recente corroboram alguns aspectos da proposta filogenética anterior (Albert et al., 2005). Em ambos os estudos, a relação entre Gymnotus e Electrophorus tem bom suporte estatístico, corroborando a monofilia da família Gymnotidae. O grupo $G$. carapo também recebe alto suporte, em todas as análises conduzidas até o presente, além disso, o complexo G. carapo (G. carapo, G. arapaima e G. ucamara) também teve sua monofilia confirmada. Entretanto, o grupo $G$. pantherinus não se mostrou consistente no trabalho de Lovejoy et al. (2010). Este grupo apresentou-se subdivido em três clados principais: o grupo G1 (grupo irmão dos demais Gymnotus; incluindo G. coropinae, G. stenoleucus, G. coatesi, G. jonasi e G. javari); o grupo G2 (G. cataniapo, G. pedanopterus e G. sp. cf. anguillaris); e, G. pantherinus. O posicionamento de G. pantherinus aparece ambíguo dentre as diversas análises, recebendo suporte estatístico invariavelmente baixo.

\section{Gymnotus pantherinus: uma espécie ou um complexo?}

Gymnotus pantherinus (Steindachner, 1908) é uma espécie facilmente diferenciada das demais espécies do gênero Gymnotus pelo seu padrão característico de coloração, formando manchas vermiculadas de tamanho variável em contraste com um fundo pouco pigmentado (figura 1.3). Apresenta ampla distribuição geográfica, tendo sua ocorrência atualmente reconhecida 
para os rios costeiros do leste, sudeste e sul do Brasil, desde riachos contribuintes do complexo Laguna dos Patos, Estado do Rio Grande do Sul (Gonçalves, 2005) até o sul do Estado da Bahia (Campos-da-Paz, 1997; Reis et al., 2003; Fonteles et al., 2005). O fato dessa espécie não estar presente no Escudo Brasileiro, sugere uma história evolutiva de extinção ou ausência de colonização dessa porção continental (Albert et al., 2005).

Os exemplares dessa espécie apresentam todas as sinapomorfias propostas para o gênero por Albert (2001) e Albert et al. (2005), sendo as mais facilmente identificáveis: boca superior com mandíbula prognata e posição dorso-lateral dos olhos. Distinguem-se dos demais membros do gênero pelo aspecto intermitente da linha lateral, que se apresenta interrompida em vários pontos ao longo de sua extensão (Gonçalves, 2005). Também apresentam a altura do corpo mais baixa em relação aos demais representantes do gênero, menor que 9\% do CFA (comprimento até o final da nadadeira anal), ausência de faixas ou bandas pelo corpo em qualquer idade e número máximo de quatro fileiras de eletrócitos presentes no tecido eletrogênico da região posterior do corpo.

G. pantherinus ocorre exclusivamente em riachos costeiros e nas porções altas das drenagens do Rio Tietê e Iguaçu. Seu habitat é caracterizado basicamente por leitos formados por rochas e pedras, águas límpidas, temperaturas relativamente baixas e alta concentração de oxigênio dissolvido. Nos trechos onde a Mata Ciliar persiste, há menor incidência de radiação solar, o que determina valores mais baixos de temperatura. A mata contribui com material vegetal alóctone, o que torna a cor água avermelhada e mais ácida, por conta do grande aporte de material orgânico em decomposição (Oyakawa et al., 
2006). Ocupam preferencialmente os trechos rasos e estreitos dos rios, isto é, as porções mais próximas das cabeceiras, seja do rio principal ou de seus tributários. Por terem hábitos noturnos, são encontrados durante o dia junto à vegetação marginal, entocados no barranco na ausência da vegetação, ou ainda protegidos em meio às pedras que constituem o leito dos rios. A noite, transitam pelo rio em busca de alimentos e reprodução.

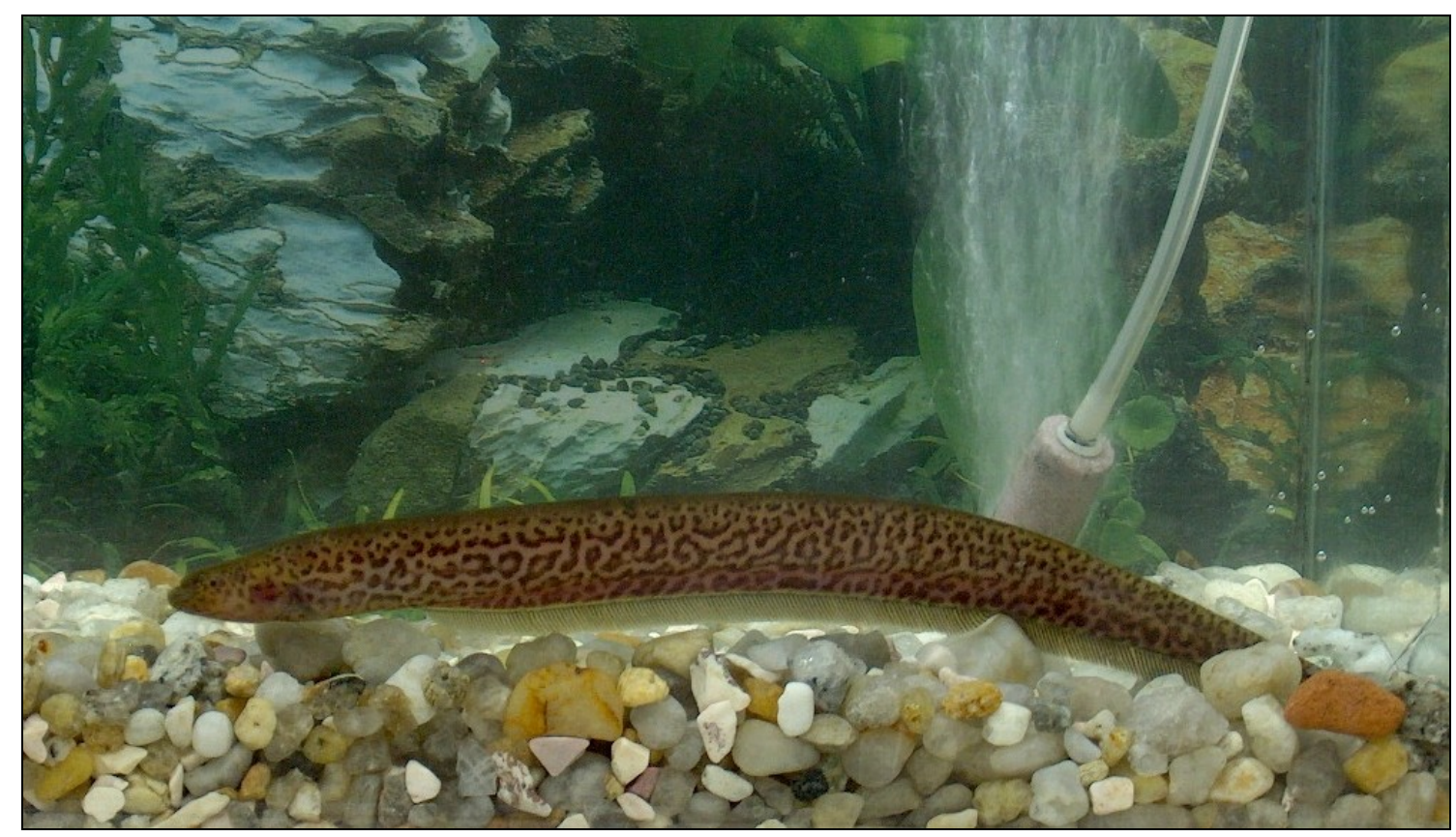

Figura 1.3 - Exemplar de Gymnotus pantherinus coletado em São Lourenço da Serra-SP, drenagem do Alto Tietê.

Campos-da-Paz (1997) analisando os Gymnotiformes das Bacias do Paraná, Paraguai, São Francisco e rios costeiros do leste do Brasil, reconheceu que indivíduos referidos de maneira tentativa a Gymnotus pantherinus, provenientes de localidades ao norte do Rio Doce (Estados do Espírito Santo e Bahia), apresentavam o corpo aparentemente mais alto do que os exemplares 
encontrados na Serra do Mar, característica que poderia ser um indicativo da ocorrência de uma nova espécie nessa região e da existência de um complexo de espécies relacionadas, hipótese reforçada por Gonçalves, em 2002 (dados não publicados).

Muitos exemplares de G. pantherinus são encontrados em coleções identificados como G. carapo, apesar das diferenças marcantes entre as duas espécies, ou simplesmente como Gymnotus sp. ou Gymnotidae. A descrição original da espécie não apresenta figuras e tem poucas informações detalhadas. Motivado por essas observações, Gonçalves (2005) realizou uma revisão morfológica do grupo, com o objetivo de gerar uma descrição detalhada de Gymnotus pantherinus, estabelecendo os limites do táxon, além de descrever novas formas pertencentes a esse complexo. Baseado em caracteres morfométricos, merísticos e em padrões de coloração, os quais foram agrupados com base em uma característica supostamente derivada, o aspecto intermitente da linha lateral, Gonçalves (2005) redescreve a espécie a partir do material-tipo e de material de comparação proveniente de outras localidades. No mesmo trabalho, são definidas quatro novas formas pertencentes ao referido Complexo Pantherinus, distribuídas na região biogeográfica do leste/sudeste do Brasil: Gymnotus "Linhares", de bacias costeiras ao norte da foz do rio Doce; Gymnotus "Itapoá”, de riachos costeiros no norte do Estado de Santa Catarina; e duas outras formas de ocorrência em contribuintes do complexo lagunar do sul do Brasil, Gymnotus "Laguna dos Patos" sp.1 e sp.2.

Segundo Gonçalves (2005), a distribuição geográfica da espécie Gymnotus pantherinus se dá em pequenas bacias costeiras entre a desembocadura do rio Paraíba do Sul e a bacia do rio Ribeira de Iguape, em 
drenagens da Serra do Mar, originalmente cobertas pela Mata Atlântica. O rio de maior porte dessa região é o Rio Paraíba do Sul, onde a espécie é encontrada freqüentemente nos trechos altos e médios desse rio e afluentes, não havendo registros de captura nas porções baixas.

\section{Origem da Diversidade Neotropical}

Compreender os processos evolutivos que originam e mantêm a alta biodiversidade neotropical tem sido um desafio para os pesquisadores por mais de um século. Essa questão pode ser abordada de duas formas: definindo os processos ecológicos responsáveis pela manutenção da alta diversidade em áreas definidas, ou ainda, definindo os processos evolutivos e biogeográficos que promoveram a diversificação ao longo do tempo e do espaço (Moritz et al., 2000).

De modo geral, as hipóteses de diversificação nos neotrópicos levam em consideração dois aspectos principais: a ocorrência de baixas taxas de extinção e/ou altas taxas de especiação. Argumenta-se que biotas tropicais tenham acumulado uma alta diversidade de espécies ao longo do tempo por ser uma região antiga e estável climaticamente (em comparação aos sistemas temperado ou boreal). Em princípio, essa hipótese é testável comparando-se o comportamento das taxas de extinção/especiação entre grupos-irmãos entre zonas tropicais e temperadas, ou entre áreas de diferente estabilidade (Moritz et al., 2000).

As hipóteses a respeito dos fatores que promovem a diversificação estão 
em essência preocupadas com o contexto geográfico da especiação ou ainda, em caso de alopatria, com os mecanismos de isolamento que promovem a diversificação. Dentre os modelos propostos, o modelo de refúgios tem sido o mais amplamente discutido (Vanzolini \& Williams, 1970; Brown \& Ab'Saber, 1979; Moritz et al., 2000). Esse modelo propõe a especiação por alopatria, em refúgios florestais isolados em decorrência da retração das florestas, durante os períodos glaciais. Acredita-se que a especiação tenha sido especialmente conduzida pela expansão de áreas abertas durante o Último Máximo Glacial, ou ainda, em períodos glaciais anteriores, e as forças evolutivas predominantes que atuaram na diversificação entre os refúgios teriam sido, nesse caso, deriva genética e seleção disruptiva. É possível imaginar que, para grande parte da biota, a retração e expansão das florestas possa ter tido uma influência direta na diversificação dos organismos, uma vez que a diminuição do hábitat resultaria na redução das populações naturais, promovendo o isolamento entre os remanescentes e o aumento da deriva genética dentro de cada refúgio. Vários estudos têm demonstrado uma correlação entre os padrões de diversidade genética e as alterações climáticas e florestais ocorridas durante o Pleistoceno. Exemplos de tais padrões são vistos em aves (Cabanne et al., 2008), anfíbios (Carnaval et al., 2009), répteis e mamíferos (Grazziotin et al., 2006; Carnaval \& Moritz, 2008). Já para a fauna aquática de um modo geral, não é clara a influência que a retração das florestas poderia ter exercido na manutenção da viabilidade dos corpos d'água e de sua fauna intrínseca. Além disso, tem sido difícil conciliar essa escala temporal com a diversificação dos peixes de água doce, que na maioria dos casos, parece ter sido anterior ao Pleistoceno (Montoya-Burgos 2003; Hubert et al. 2007; Menezes et al., 2008; Cardoso \& 
Montoya-Burgos, 2009).

Um segundo modelo de diversificação leva em consideração a existência de sistemas hídricos compondo barreiras à dispersão e ao fluxo gênico. Populações isoladas em cada margem do rio tendem a ser tornar gradativamente divergentes, desde que não haja fluxo gênico ou que esse seja restrito, até se tornarem espécies diferentes. Suporte empírico para esse modelo vem da observação de que os limites de espécies ou subespécies intimamente relacionadas muitas vezes coincidem com os principais rios da Amazônia. Tal padrão tem sido recorrentemente relatado para saguis e micos (Hershkovitz, 1977), várias aves (Haffer, 1978; Haffer, 1992; Haffer, 1997) e lagartos amazônicos (Avila-Pires, 1995; Moritz et al., 2000). Em outras regiões hidrográficas, rios de grande porte parecem também ter relação com a divergência entre clados, como proposto por Pellegrino et al. (2005). Em um estudo filogeográfico realizado com lagartos da Mata Atlântica, Gymnodactylus darwinii, os autores demonstraram a existência de três filogrupos, cujo padrão de estrutura genética coincide com a presença de importantes sistemas hídricos da região (São Francisco, Paraguaçu, Jequitinhonha, Doce e Paraíba do Sul). Outros exemplos de lagartos que têm sua distribuição limitada pelos mesmos rios são Tropidurus hispidus e Tropidurus hygomi, que não ocorrem ao sul do Rio Paraguaçu, Strobilurus torquatus, que não ocorrem ao sul do Rio Doce e Coleodactylus meridionalis, que tem sua distribuição limitada ao norte do Rio Jequitinhonha (Rodrigues, 1987; Rodrigues, 1990). Embora pareça que os rios afetem apenas a distribuição dos organismos terrestres, a dispersão das espécies de peixes de água doce com comportamentos ecológicos particulares pode também ser influenciada pelos rios de grande porte (Hubert \& Renno, 2006). 
Por outro lado, a hipótese dos rios como barreiras apresenta também algumas controvérsias. Primeiramente porque ao longo de sua extensão, um rio apresenta diferenças significativas em sua conformação, seja em largura ou profundidade, o que afetará de modo diferencial as populações que habitam suas margens. Dessa forma, cada trecho do rio atua de modo particular sobre a estrutura das populações, podendo em alguns trechos ser menos efetivo do que em outros, onde permitiria fluxo gênico pelo menos parcialmente. Outro aspecto importante é que a origem e remodelagem dos rios está estreitamente relacionada com movimentos tectônicos de remodelagem do relevo, e separar tais componentes da história evolutiva dos organismos é uma tarefa praticamente impossível. Além disso, na Mata Atlântica, áreas compreendidas entre os principais rios são congruentes com as áreas preditas como remanescentes florestais do Pleistoceno, logo, torna-se difícil distinguir entre tais hipóteses alternativas.

Finalmente, uma outra importante hipótese de diversificação relaciona eventos paleogeográficos como principais eventos vicariantes. Postula-se que atividades geotectônicas associadas à formação e remodelagem do relevo, como a Cordilheira dos Andes e a Serra do Mar, por exemplo, sejam responsáveis pela separação de populações e subseqüente diferenciação, principalmente quando se trata de divergências mais profundas (pré-Pleistoceno) (Grazziotin et al., 2006). Mudanças geomorfológicas inevitavelmente acarretam alterações nos cursos dos rios, ou ainda, na captura de drenagens por sistemas adjacentes (Montoya-Burgos, 2003; Hubert \& Renno, 2006; Ribeiro, 2006), constituindo um importante agente vicariante para os organismos aquáticos.

Em relação à ictiofauna, Weitzman et al. (1988) sugeriram que a 
especiação em Glandulocaudini (Characidae), e também em outras espécies de peixes presentes nas drenagens costeiras do Brasil, fosse resultante de um complicado sistema vicariante associado às flutuações do nível do mar ocorridas durante períodos glaciais e interglaciais do Pleistoceno. Entretanto, Menezes et al. (2008), revisitando o grupo em estudo baseado em dados morfológicos e moleculares, afirmam que o principal padrão de diversificação do grupo está claramente associado aos principais aspectos da evolução tectônica da porção sul da plataforma Sul-Americana Cis-Andina.

Evidentemente, os fatores que promovem a diversificação da fauna atuam de forma diferente em espécies diferentes, respeitando as características biológicas, ecológicas e reprodutivas de cada grupo. A intensidade da vicariância está diretamente associada à capacidade de dispersão de cada organismo, de modo que pode ser mais ou menos intensa em espécies diferentes que ocupam o mesmo hábitat. Indiscutivelmente, quando se trata de peixes de água doce, processos geomorfológicos responsáveis pela remodelagem das bacias hidrográficas constituem o fator primordial de diversificação, por meio da vicariância ou coalescência de linhagens biológicas. Entretanto, não necessariamente este seja o único fator responsável pela riqueza em espécie encontrada nos dias atuais.

\section{Biogeografia Histórica das Drenagens Costeiras Brasileiras}

A riqueza da fauna de peixes de água doce Neotropicais é resultado de milhões de anos de evolução desde a separação da Gondowana até os dias 
atuais, entretanto, muito pouco ainda se sabe a respeito dos processos que promoveram tal diversificação. Vari \& Weitzman (1990) atribuíram essa deficiência de hipóteses principalmente à falta de informação a respeito da sistemática, história filogenética e distribuição geográfica precisa para a maioria das espécies de peixes Neotropicais. Com o passar dos anos e mesmo com o aumento crescente dos estudos em Sistemática e Biogeografia, Ribeiro (2006) reconhece ainda um outro problema: a dificuldade de se associar as hipóteses filogenéticas existentes à história geológica do continente. Segundo Ribeiro (2006), a dificuldade dos biólogos em entender e sintetizar os processos geológicos constitui uma séria limitação ao nosso conhecimento sobre a biogeografia dos peixes de água doce Neotropicais.

A biogeografia histórica dos peixes de água doce fornece uma ligação natural entre a evolução biótica e geomorfológica de uma região, uma vez que a dispersão dos peixes depende exclusivamente das conexões entre os rios, e tais conexões são uma conseqüência direta dos processos geológicos ocorridos nessa região (Lundberg, 1993). O maior sistema de drenagens da América do Sul, por exemplo, desenvolveu sua atual conformação após vários episódios tectônicos, iniciados a cerca de 89 Ma atrás e culminando com a formação final dos Andes por volta de 10 Ma. Assim, a diversificação da fauna aquática foi dirigida pela ocorrência de múltiplos eventos de vicariância tanto quanto coalescência dos sistemas hídricos (Lundberg et al. 1998; Sivasundar et al., 2001).

As maiores implicações biogeográficas para os organismos aquáticos da América do Sul são decorrentes da formação das paleodrenagens do escudo cristalino brasileiro. De acordo com o modelo proposto por Cox (1989), durante o processo de separação entre os continentes Americano e Africano, alterações 
térmicas (conhecidas como Pluma Mantélica) desencadearam uma deformação arqueada por centenas de quilômetros de extensão durante a fase inicial de falhamento, o que impôs um característico padrão de drenagem, com rios correndo a partir do centro dessas deformações. Esse processo supostamente atuou em várias porções das margens continentais da África e América do Sul, dando origem a seis principais megadomos (1. Guiana/Guiné; 2. Nordeste Brasileiro/Nigéria; 3.Mantiqueira/Angola; 4. Uruguai/Sudoeste Africano; 5. Somuncurá; e, 6. Puerto Deseado). Tal padrão de drenagem se faz evidente até os dias atuais, como visto no Rio Paraná e nas cabeceiras do rio São Francisco. Além desses rios que evoluíram ao longo da borda da deformação arqueada, reativações tectônicas resultaram em drenagens que desenvolveram longas e sinuosas rotas sobre o escudo cristalino brasileiro ancestral, antes que desaguássem no recém aberto Oceano Atlântico (Potter, 1997; Ribeiro, 2006).

Com a separação completa da Gondowana, iniciou-se a história independente dos rios da margem Atlântica da América do Sul. Os rios que constituem as drenagens costeiras do leste/sudeste/sul do Brasil, formam uma série de bacias hidrográficas isoladas, compostas pelos seguintes sistemas hidrográficos primários: Paraguaçu, Contas, Jequitinhonha, Doce, Paraíba do Sul, Ribeira de Iguape, Itajaí e Jacui. Estes rios, ao lado de outras bacias menores, estão separados do escudo cristalino brasileiro por paisagens escarpadas e montanhosas (Ribeiro, 2006).

Segundo Cobbold et al. (2001), a idéia tradicional de que a margem Atlântica Brasileira constitui uma margem passiva, contrasta com o contexto tectônico que caracteriza a região. Um grande número de eventos sísmicos são relatados para o sudeste brasileiro e regiões vizinhas, datados do fim do 
Cretáceo e Cenozóico. Padrões topográficos e drenagens são evidências de soerguimentos recentes, falhamentos e captura de rios, tudo isso como resultado de tectonismo ativo. No interior do continente, a crosta se mostra mais espessa do que o esperado para uma margem falhada, provavelmente decorrente do encurtamento sofrido no Cenozóico como resultado de uma tensão compressional lateral. Já a litosfera do sudeste do Brasil é relativamente mais fraca em relação às áreas cratônicas adjacentes, o que pode explicar porque essa região é sismicamente ativa e propensa a deformações.

Um sumário dos eventos tectônicos ocorridos no Brasil durante o Quaternário apresentado por Riccomini \& Assumpção (1999) aponta a existências de falhas em quase todas as províncias geológicas brasileiras. Dentre elas, o Rifte Continental do Sudeste do Brasil sofreu o mais pronunciado evento de reativação de antigas linhas estruturais e formação de novas falhas. Tais atividades tectônicas do Quaternário promoveram, entre outras mudanças topográficas, rearranjos hidrográficos recentes decorrentes da captura de drenagens.

As Drenagens Costeiras do leste, sudeste e sul do Brasil correspondem a áreas de grande significado biogeográfico, apresentando um alto grau de endemismo em sua fauna de peixes. Padrões filogenéticos sugerem uma relação próxima entre os rios que correm para o Atlântico com os rios adjacentes das terras altas do escudo cristalino. Entretanto, pouco tem sido dito sobre a dinâmica dos processos geológicos relacionados aos eventos cladogenéticos entre estas áreas, embora, padrões de distribuição e filogenéticos sugiram uma íntima associação com a história geológica da margem continental passiva da América do Sul, desde o Cretáceo aos dias atuais (Ribeiro, 2006). 


\section{O estado de conservação dos riachos de Mata Atlântica}

A Floresta Atlântica, ou Mata Atlântica como é conhecida no Brasil, ocupa a categoria de segundo grande complexo de florestas tropicais biodiversas brasileiras. É composta por muitos tipos e sub-tipos de florestas, tropicais ou subtropicais, em sua maioria florestas pluviais, mas não em toda sua área de distribuição. Dada a sua extensão, engloba grande diversidade climática e topográfica, resultando em um ambiente heterogêneo, o qual abriga uma expressiva diversidade de espécies, exibindo também um alto grau de endemismo (Oyakawa et al., 2006). Tais características associadas à acentuada devastação e fragmentação florestal que tem sofrido, faz com que a Mata Atlântica apresente os mais elevados números de espécies ameaçadas de extinção. Em sua estruturação espacial primária, a Floresta Atlântica abrangia aproximadamente um milhão de quilômetros quadrados (Ab'Saber, 2003), embora atualmente, constitua um dos biomas mais ameaçados do mundo, restando apenas cerca de $5 \%$ de sua cobertura vegetal original. Mais de $60 \%$ das espécies mencionadas na Lista Vermelha da Fauna Brasileira Ameaçada de Extinção (MMA, 2009) têm distribuição conhecida nesse bioma. Em relação à Flora, mais de $55 \%$ das espécies ameaçadas de extinção também pertencem à Mata Atlântica (MMA, 2008). Apesar disso, o reconhecimento de cuidados especiais para conservação do ambiente aquático e dos grupos que nele existem nas florestas tropicais tem sido amplamente negligenciado (Menezes et al., 2007). Justificativas para a conservação das florestas são usualmente associadas a diversidade de plantas e vertebrados terrestres, enquanto pouca preocupação tem sido demonstrada em relação aos peixes de água doce (Maitland, 1995). O 
que normalmente se esquece é que a sobrevivência dos peixes, que se alimentam de invertebrados ou plantas alóctones ou demandam de certas condições físicoquímicas da água propiciadas pelo ambiente externo, dependem da conservação das florestas para sua sobrevivência (Menezes et al. , 2007).

De toda a biodiversidade encontrada na Mata Atlântica, os peixes são os menos conhecidos do público geral, porque ocorrem em ambientes aquáticos bastante restritos, além de serem pequenos e com hábitos crípticos, ocultandose sob pedras ou sob a vegetação ribeirinha. Pelo pequeno tamanho se tornam desinteressantes para a pesca, passando despercebidos pela maioria dos pescadores, até mesmo dos mais experientes (Oyakawa et al., 2006).

Embora pouco conhecidos, os peixes dos riachos da Mata Atlântica representam um grande número de espécies, das mais variadas formas, cores e hábitos. Estes peixes mantêm um estreito vínculo com a floresta e sua sobrevivência, depende da preservação da Mata Atlântica e da conservação da qualidade e da quantidade das águas, seja pelo suprimento de alimentos, pela manutenção da temperatura ou das condições físico-químicas da água, entre outros fatores. A destruição das matas expõe os peixes à luz direta do sol e aos seus predadores, além de diminuir drasticamente a oferta de alimentos. A floresta é ainda de extrema importância para a manutenção dos cursos d'água, pois o solo da floresta age como uma esponja, mantendo o nível de saturação relativamente alto, fazendo com que o suprimento de água aos riachos e córregos seja contínuo (Oyakawa et al., 2006; Menezes et al., 2007). Nessas condições, riachos de pequeno porte, os quais são a grande maioria constituintes das drenagens costeiras, possuem água o ano todo.

A ausência da cobertura vegetal, além de alterar o ciclo hidrológico, 
reduzindo a quantidade de água no período de seca, provoca grandes enxurradas no período chuvoso, agravando o processo erosivo dos solos. Além do aporte de sedimentos erodidos promover o assoreamento dos rios, provoca também a turbidez das águas, antes límpidas e transparentes. A homogeneidade do substrato decorrente do assoreamento reduz a diversidade local porque espécies reofílicas são desfavorecidas pela diminuição do substrato rochoso, enquanto espécies generalistas e adaptadas a solo arenoso, são favorecidas (Casatti et al., 2006, 2009). Por outro lado, o aumento na turbidez das águas pode afetar os padrões de abundância e distribuição das espécies visualmente orientadas, porque a transparência da água determina as condições de visibilidade subaquáticas e as respostas dos peixes às variações espaciais e temporais, a qual são adaptados (Menezes et al., 2007; Melo et al., 2009).

Não só o desmatamento tem sido uma ameaça aos sistemas aquáticos atualmente. $\mathrm{O}$ crescimento das cidades, das indústrias e da agricultura, tem também provocado a poluição dos rios e riachos, seja pelo aporte de esgoto doméstico e/ou industrial, ou ainda, pela contaminação das águas por pesticidas. A poluição por esgoto doméstico causa a eutrofização das águas e conseqüentemente a redução do oxigênio dissolvido. A contaminação por esgoto industrial ou pesticidas contaminam quimicamente as águas, interferindo diretamente na saúde de todos os organismos aquáticos.

Diante de alterações ecológicas tão severas, as populações de peixes sensíveis a estes fatores podem ser drasticamente reduzidas ou mesmo extintas localmente (Sarmento-Soares et al., 1996). Embora os efeitos negativos da degradação ambiental sobre os rios e riachos sejam bem conhecidos e documentados, suas reais implicações às comunidades de peixes dos riachos de 
Mata Atlântica são difíceis de serem mensuradas, porque os hábitos particulares de cada espécie faz com que respondam de modo diferencial aos efeitos da degradação/poluição. Além disso, os riachos costeiros são marcados por uma considerável diversidade de hábitats, seja decorrente da altitude, declividade, largura e profundidade da calha, temperatura e aporte de nutrientes. Ao longo de sua extensão, um riacho costeiro pode apresentar desde nascentes, corredeiras, cachoeiras e poços em altitudes mais elevadas, até brejos e poças temporárias em altitudes mais baixas (Gerhard et al., 2004; Oyakawa et al., 2006) e cada hábitat será mais ou menos prejudicado pelos efeitos da degradação dependendo de suas características ecológicas. De um modo geral, o que se sabe é que as alterações ambientais reduzem a taxa de riqueza de espécies a poucos grupos generalistas ou tolerantes às novas condições ambientais impostas (Couceiro et al., 2007).

A alteração do hábitat em grande escala constitui ainda um grave problema para aqueles que estudam aspectos históricos da evolução e distribuição dos peixes nas regiões de Mata Atlântica. Além disso, segundo Menezes et al. (2007), a sistemática e biogeografia desses peixes não foram estudadas em profundidade, a não ser muito recentemente, o que dificulta ainda mais a visualização de padrões. Muitas espécies novas de peixes têm sido descritas nos últimos anos e acredita-se que muitas outras venham a ser descritas a medida que os esforços de coleta sejam ampliados. Segundo Menezes et al. (2007) o que temos no momento é um conhecimento fragmentado dos efeitos resultantes da degradação e destruição da Mata Atlântica sobre a fauna de peixes, depois de quase 500 anos de ocupação humana. A falta de conhecimento prévio sobre o estado original da ictiofauna torna falha nossa 
estimativa sobre a perda da diversidade. $\mathrm{O}$ modo de se abordar esse assunto atualmente é comparando áreas onde a floresta foi preservada em sua integridade com áreas adjacentes degradadas. Entretanto, poucas áreas permanecem intocadas, de modo que as comparações não são totalmente satisfatórias.

Algumas características dos peixes de água doce, bem como de outros organismos aquáticos, são especialmente relevantes quando o assunto é conservação. Os hábitats são relativamente restritos à dispersão (mantendo-se as devidas proporções) e os organismos vivem confinados dentro de limites determinados (Maitland, 1995). Esse confinamento é acentuado nos riachos de Mata Atlântica, que apresentam leitos estreitos em sua grande maioria, principalmente quando se consideram as porções mais altas das drenagens e as regiões de cabeceiras. Isso conduz à diferenciação de muitas populações independentes, já que as populações perdem o contato entre si e o fluxo gênico cessa ou se torna reduzido.

Segundo Maitland (1995), as populações de peixes de água doce habitam unidades descontínuas, muitas vezes pequenas, dentro das quais há um significante movimento das águas, o que torna o hábitat de certa forma homogêneo, e assim, a população toda fica vulnerável aos efeitos da poluição e da degradação do hábitat. Esse fato faz com que a situação das espécies de peixes da Mata Atlântica seja ainda mais preocupante, já que o isolamento entre as populações tende a ser maior decorrente do tamanho limitado das drenagens e da baixa conectividade entre elas, e também porque o ambiente tem sido gradativamente agredido pelo crescimento das cidades e conseqüente devastação das florestas, além do descarte de poluentes urbanos e industriais 
nos corpos d'água.

Um dos grandes desafios conservacionistas está em estabelecer formas de preservação de um alto número de espécies dentro de um custo aceitável. Dessa forma, a definição de hotspots de diversidade, onde excepcional concentração de espécies endêmicas possa ser encontrada, parece ser uma abordagem promissora (Myers et al., 2000). Em relação aos peixes dos riachos de Mata Atlântica, Menezes et al. (2007) relatam que há uma grande dificuldade em se delimitar áreas de endemismo, pois, por definição, uma área de endemismo é uma área onde dois ou mais organismos sem interações mutualistas ou parasitárias entre si apresentam uma sobreposição completa em suas distribuições, algo que na realidade é bastante difícil de ser provado. Parte do problema está na deficiência do conhecimento dos padrões de distribuição das espécies de peixes da Mata Atlântica, dada a escassez de trabalhos desenvolvidos na região. Ainda assim, os sistemas de rios costeiros do leste brasileiro têm sido considerados como uma área de endemismo por diversos autores (Eigenmann, 1908; Vari, 1988; Menezes, 1996).

Os principais objetivos dos programas de conservação, fortalecidos por uma legislação eficiente, devem promover a recuperação e o gerenciamento dos hábitats. Enquanto isso, medidas a curto prazo podem ser úteis para minimizar os danos ambientais a longo prazo. Tais medidas incluem translocações de fauna, criação em cativeiro de espécies e reintrodução, ou ainda, a criopreservação de germoplasma (Maitland, 1995). Obviamente, decisões sobre o manejo de populações devem ser tomadas com base na história evolutiva do grupo e na acurada avaliação de seu status taxonômico, visando à preservação das espécies com entidades dinâmicas e capazes de se adaptarem às mudanças 
naturais do ambiente (Frankham et al., 2008).

Em resumo, e de acordo com Menezes et al., (2007), os efeitos do desmatamento sobre as populações de peixes tropicais associados à floresta pluvial, não têm sido suficientemente estudados, embora observações de campo têm demonstrado que é menor o número e a variedade de peixes encontrados em áreas desmatadas quando comparadas com áreas florestadas.

Não ambicionamos salvar todos os peixes em perigo ou ameaçados, mas é importante tentar preservar a maior parcela possível da diversidade que ainda nos resta, havendo uma necessidade urgente da realização de estudos e levantamentos faunísticos, visando identificar de modo preciso prioridades de conservação dos ambientes aquáticos das regiões de Mata Atlântica do Brasil.

Esperamos que o presente trabalho possa contribuir para o entendimento dos padrões de diversificação e evolução de Gymnotus pantherinus, bem como para o gênero Gymnotus e ainda, futuramente, possa também contribuir para a conservação dos ambientes aquáticos da Floresta Atlântica Brasileira. 


\section{Objetivos}

O presente trabalho teve como objetivo principal o estudo sistemático e filogeográfico do complexo de espécies Gymnotus pantherinus (Complexo Pantherinus), provenientes das Bacias do Atlântico Leste e Sudeste do Brasil, utilizando marcadores moleculares nucleares e mitocondriais.

Os objetivos específicos desse trabalho foram:

1. Avaliar o status taxonômico de Gymnotus pantherinus com base em marcadores moleculares;

2. Avaliar a diversidade genética das populações, a existência de fluxo gênico e os níveis de estruturação entre as populações de Gymnotus pantherinus;

3. Verificar possíveis barreiras geográficas que possam ter influenciado a atual distribuição das populações e a eventual diversificação da espécie;

4. Testar a hipótese de captura de cabeceiras envolvendo as drenagens em estudo e analisar o efeito da Serra do Mar na diferenciação das populações;

5. Caracterizar Unidades Evolutivas Significantivas, que sirvam como referência para programas de manejo e conservação da região em estudo. 
No presente trabalho, foram utilizadas ferramentas moleculares para a avaliação do status taxônomico do Complexo Pantherinus e para o estudo da diversidade genética, estrutura populacional e padrões demográficos de Gymnotus pantherinus (senso estrito). Esse constitui o primeiro estudo filogeográfico para espécies de peixes dos riachos da Mata Atlântica.

- Nossos resultados mostram que o Complexo Pantherinus é composto por cinco linhagens geográficas estatisticamente significantes, das quais aquela representada por espécimes da Bahia e Espírito Santo é a que apresenta maior divergência. Sugere-se que essa linhagem seja reconhecida como uma nova espécie, reforçando a proposta prévia de Campos-da-Paz (1997) e Gonçalves (2005) baseada na análise de caracteres morfológicos.

- As demais linhagens, dentre as quais a mais recente é a linhagem de $G$. pantherinus (senso estrito), foram consideradas como espécies incipientes, demonstrando um aspecto gradual do processo de especiação.

- As linhagens de G. pantherinus evidenciadas pelos dados moleculares não foram identificadas pelas análises morfológicas conduzidas por Gonçalves (2005). Os clados 2 (Norte de SP), 3 e 4 (RJ), recuperados pelos dados moleculares, não apresentaram variação morfológica significativa. 
- Ainda em oposição aos resultados de Gonçalves (2005), os dados moleculares não corroboram a linhagem de São Francisco do Sul - SC como uma nova espécie. Ao contrário, os haplótipos recuperados para essa localidade apresentam-se contidos no clado 5, que é o clado de divergência mais recente e que representa G. pantherinus, senso estrito.

- A cladogênese associada ao processo de divergência entre as espécies, definidas pelo presente estudo, parece estar relacionada à presença do Rio Doce como agente vicariante. As demais linhagens de G. pantherinus parecem ter seu processo de diversificação associado barreiras geográficas, resultantes da conformação da Serra do Mar.

- De um modo geral, populações associadas ao Vale do Ribeira apresentaram altos valores de diversidade genética, tanto haplotípica quanto nucleotídica. É nessa região que a planície costeira se apresenta mais extensa, permitindo maior mobilidade aos rios e possivelmente populações com tamanhos efetivos maiores. Por outro lado, populações localizadas em regiões mais elevadas, presentes em riachos encaixados na porção serrana, apresentam índices de diversidade bem menores, possivelmente pelo maior isolamento dessas populações.

- As populações de G. pantherinus mostraram-se altamente estruturadas, apresentando baixo compartilhamento de haplótipos e muitos haplótipos exclusivos. Valores significativos de estruturação foram obtidos tanto pelos valores de Fst e pelo Teste Exato de Diferenciação, quanto pelos resultados da AMOVA. 
- O padrão de relacionamento entre os haplótipos demonstra a existência de três linhagens principais, com clara associação geográfica, sendo elas: (1) Rio de Janeiro; (2) Norte de São Paulo; e, (3) Centro-Sul de São Paulo, Paraná e Santa Catarina.

- Dentro de cada clado principal, os haplótipos mostraram-se parafiléticos, não havendo a mesma associação geográfica verificada entre os clados. Esse padrão filogenético sugere um processo de diversificação recente para as populações de G. pantherinus.

- Evidências de expansão populacional em Subaúma-SP foram fornecidas pelo teste de neutralidade $F s(\mathrm{Fu})$ e pelo padrão em estrela do relacionamento entre os haplótipos amostrados nessa localidade. Já a população de Cananéia, apresentou valores significativamente positivos para os testes $D^{*}$ e $F^{*}$ (Fu \& Li), o que pode sugerir um processo de gargalo populacional recente. Para as demais populações, nenhuma assinatura demográfica significativa foi encontrada.

- O grupo que representa as drenagens do Alto Tietê, Alto Paraíba do Sul e Alto Ribeira de Iguape (Engenheiro Marcilac-SP, Juquitiba-SP, Natividade da Serra-SP, Piquete-SP e São Lourenço da Serra-SP) apresenta um padrão filogeográfico interessante. Tais populações compartilham entre si um único haplótipo, o qual se apresenta derivado em relação aos demais haplótipos amostrados para G. pantherinus. Esse padrão pode ser resultante de uma colonização recente, a partir um número reduzido de fundadores (efeito fundador), sugerindo que processos tectônicos recentes 
tenham remodelado as drenagens, promovendo a dispersão/conexão de linhagens entre planalto e planície, em ambos os sentidos.

- A configuração da Serra do Mar teve papel histórico na diversificação do grupo, possivelmente determinando o padrão de diversificação entre os clados principais de G. pantherinus.

- Alterações do nível do mar, ocorridas em decorrência do Último Máximo Glacial, parece ser a explicação mais plausível para o padrão de divergência recente recuperado pelo clado $\mathrm{SP} / \mathrm{Sul}$.

- A degradação ambiental e a conseqüente redução dos hábitats naturais pode ter influência determinante na redução populacional e na perda da diversidade genética. Registramos no presente estudo que muitas populações de G. pantherinus apresentam valores baixos de diversidade genética, muitas delas caracterizadas por um padrão haplotípico monomórfico. Apesar do marcador mitocondrial utilizado neste estudo apresentar uma taxa de evolução relativamente baixa e conseqüentemente insuficiente para se mensurar os efeitos tão recentes decorrentes da ocupação humana, a baixa diversidade registrada é no mínimo sugestiva de tais eventos de redução populacional.

- O alto grau de isolamento identificado entre as populações de $G$. pantherinus tem implicações diretas na conservação dessa espécie. Estratégias de conservação contemplam a manutenção da estabilidade populacional, a restauração do fluxo gênico entre populações 
antropogenicamente fragmentadas e até mesmo a translocação de espécies para áreas não ameaçadas. Uma estratégia em potencial é priorizar a preservação de áreas onde a persistência das populações seja mais provável, a qual possa servir como fonte de recolonização de localidades menos estáveis. Seja qual for a estratégia a ser empregada, o conhecimento sobre o comportamento natural dessas populações é indispensável, desde a compreensão dos níveis de diversidade genética, estruturação populacional, fluxo gênico e dos padrões de diversificação.

- Nossos resultados demonstram a existência de pelo menos cinco Unidades Evolutivas Significativas para G. pantherinus, as quais devem ser priorizadas no que se refere à medidas de preservação dos riachos de Mata Atlântica.

Acreditamos que o conhecimento taxonômico e da história evolutiva das populações sejam indispensáveis para qualquer decisão a respeito do manejo e da conservação das espécies, priorizando a manutenção da diversidade genética de modo que as espécies tenham condições de se aptarem ao ambiente em suas constantes modificações. Dessa forma, a preservação dos hábitats e das condições ecológicas essenciais para a sobrevivência das espécies nos parece ser o caminho mais adequado. 


\section{Resumo}

Gymnotus pantherinus é uma espécie de peixe endêmica das drenagens costeiras brasileiras com distribuição desde o sul da Bahia até o Rio Grande do Sul, embora evidências morfológicas sugiram que esse táxon constitua um complexo de espécies. No presente trabalho, foram conduzidas análises filogenéticas com base em marcadores moleculares, mitocondriais e nucleares, com o objetivo de avaliar o status taxonômico do grupo. Padrões demográficos foram também inferidos para as populações de Gymnotus pantherinus (senso estrito). As análises filogenéticas sob o critério de Parcimônia, bem como as inferências bayesianas, mostraram que o grupo é composto por cinco linhagens geográficas estatisticamente bem suportadas. Das cinco linhagens identificadas, aquela composta por espécimes da Bahia e Espírito Santo é também suportada por evidências morfológicas, a qual propomos que seja reconhecida como uma nova espécie. As demais linhagens, das quais a mais recente é a de Gymnotus pantherinus senso estrito, foram consideradas como espécies incipientes. As análises populacionais revelaram que as populações de Gymnotus pantherinus (senso estrito) se apresentam altamente estruturadas, exibindo um alto índice de fixação e baixo compartilhamento de haplótipos, sendo reconhecidas três linhagens principais com alta associação geográfica. A maior diversidade genética foi encontrada na região do Vale do Ribeira e o clado SP/Sul é o que apresenta a divergência mais recente, a qual pode ter ocorrido após o Último Máximo Glacial (UMG). Populações localizadas a oeste da Serra do Mar (Paraíba do Sul, Alto Tietê e Alto Iguaçu) demonstram maior similaridade com drenagens adjacentes a leste, o que reforça a hipótese de captura de cabeceiras entre drenagens previamente postulada a partir do compartilhamento de fauna. Finalmente, os resultados apontam a existência de pelo menos cinco Unidades Evolutivas Significativas para a espécie, tendo implicações importantes na conservação dos riachos de Mata Atlântica. 
Gymnotus pantherinus is an endemic fish species found in the Brazilian coastal drainages occurring from Bahia to Rio Grande do Sul states. Morphological evidence has suggested that Gymnotus pantherinus might constitute a species complex. In the present study, the taxonomic status of Gymnotus species group has been evaluated using both mitochondrial and nuclear markers. Demographic patterns have also been inferred for the Gymnotus pantherinus populations (stricto sensus). Parsimony and Bayesian phylogenetic inferences showed that the group is composed of five well supported geographic lineages. From those, a well supported lineage constituted by the specimens from Bahia and Espírito Santo states is also corroborated by morphological data. Thus, it is suggested that this lineage be recognized as a new species within Gymnotus. The other lineages, from which the most recent representative is the Gymnotus pantherinus lineage itself, have been considered as incipient species. The population analysis showed highly structured populations with low number of shared haplotypes and three main phylogenetic lineages with high geographic association. The higher genetic diversity was found in the Ribeira Valley region, while the clade $\mathrm{SP} /$ South was the most recently diverged, which may have occurred after the Last Glacial Maximum. Populations occurring west of the Serra do Mar were more closely related to the adjacent east drainages, which strengthens the hypothesis of headwaters stream capture. Finally, at least five evolutionary significant units can be recognized, with important implications for the conservation of Atlantic Forest streams. 


\section{Referências Bibliográficas}

\section{CAPÍTULO I}

Ab'Saber, A.N. 2003. Os domínios de natureza no Brasil: potencialidades paisagísticas. São Paulo: Ateliê Editorial. 159 p.

Albert, J.S; Campos-da-Paz, R. 1998. Phylogenetics systematics of Gymnotiformes with diagnoses of 58 clades: a review of available data. In: Malabarba, L.R; Reis, R.E; Vari, R.P; Lucena, Z.M; Lucena, C.A (Eds.). Phylogeny and classification of Neotropical Fishes. Porto Alegre: EDIPUCRS. p. 419-446.

Albert, J.S. (2001). Species diversity and phylogenetic systematics of American knifefishes (Gymnotiformes, Teleostei). Misc. Publ. Mus. Zool. University of Michigan, 190, 1-129.

Albert, J.S., \& Crampton, W.G. (2003). Seven new species of the Neotropical electric fish Gymnotus (Teleostei, Gymnotiformes) with a redescription of G. carapo (Linnaeus). Zootaxa, $287,1-54$.

Albert, J.S., Crampton, W.G., Thorsen, D.H., \& Lovejoy, N.R. (2005). Phylogenetic systematics and historical biogeography of the Neotropical electric fish Gymnotus (Teleostei: Gymnotidae). Systematics and Biodiversity, 2, 375-417.

Albert, J.S, \& Fink, W.L. (2007). Phylogenetic relationships of fossil neotropical electric fishes (Ostheichthyes: Gymnotiformes) from the upper Miocene of Bolivia. Journal of Vertebrate Paleontology, 27 (1), 17-25.

Brown, K.S., \& Ab'Saber, A.N. (1979). Ice-age forest refuges and evolution in Neotropics: correlation of paleoclimatological, geomorphological and pedological data with biological endemism. Paleoclimas, 5, 1-30.

Cabanne, G. S., Horta, F. M., Sari, E. H., Santos, F. R., \& Miyaki, C. Y. (2008). Molecular Phylogenetics and Evolution Nuclear and mitochondrial phylogeography of the Atlantic forest endemic Xiphorhynchus fuscus (Aves: Dendrocolaptidae): Biogeography and systematics implications. Molecular Phylogenetics and Evolution, 49, 760-773. Elsevier Inc. doi: 10.1016/j.ympev.2008.09.013.

Campos-da-Paz, R. (1997). Sistemática e taxonomia dos peixes elétricos das bacias dos rios Paraguai, Paraná e São Francisco, com notas sobre espécies presentes em rios costeiros do leste do Brasil (Teleostei: Ostariophysi: Gymnotiformes). Tese de Doutorado. Instituto de Biociências, Universidade de São Paulo, São Paulo. 336 p.

Campos-da-Paz, R. (2003). Family Gymnotidae. In: Reis, R.E., Kullander, S.O., \& Ferrari-Jr, C.J. Check list of the freshwater fishes of South and Central America. Porto Alegre: 


\section{EDIPUCRS, $742 \mathrm{p}$.}

Cardoso, Y. P. \& Montoya-Burgos, J.I. (2009). Unexpected diversity in the catfish Pseudancistrus brevispinis reveals dispersal routes in a Neotropical center of endemism: the Guyanas Region. Molecular Ecology, 18, 947-964.

Carnaval, A.C. \& Moritz, C. (2008). Historical climate modelling predicts patterns of current biodiversity in the Brazilian Atlantic forest. Journal of Biogeography, 35, 1187-1201.

Carnaval, A.C., Hickerson, M.J., Haddad, C.F., Rodrigues, M.T. \& Moritz, C. (2009). Stability Predicts Genetic Diversity in the Brazilian Atlantic Forest Hotspot. Science, 323, 785-789.

Casatti, L., Langeani, F., Silva, A. M., \& Castro, R. M. (2006). Stream fish, water and habitat quality in a pasture dominated basin, Southeastern Brazil. Brazilian Journal of Biology, 66(2B), 681-696.

Casatti, L., Ferreira, C. P., \& Langeani, F. (2009). A fish-based biotic integrity index for assessment of lowland streams in southeastern Brazil. Hydrobiologia, 623, 173-189. doi: 10.1007/s10750-008-9656-x.

Cobbold, P.R., Meisling, K.E. \& Mount, V.S. (2001). Reactivation of an obliquely rifted margin, Campos and Santos basins, southeastern Brazil. AAPG Bulletin, 85, 1925-1944.

Couceiro, S. R., Hamada, N., Luz, S. L., Forsberg, B. R., \& Pimentel, T. P. (2007). Deforestation and sewage effects on aquatic macroinvertebrates in urban streams in Manaus, Amazonas, Brazil. Hydrobiologia, 575, 271-284. doi: 10.1007/s10750- 006-0373-z.

Cox, K. G. (1989). The role of mantle plumes in the development of continental drainage patterns. Nature, 342, 873-876.

Crampton, W. G. R., Thorsen, D. H., \& Albert, J. S. (2005). Three new species from a diverse sympatric assemblage of Gymnotus (Gymnotiformes: Gymnotidae) in the lowland Amazon basin, with notes on ecology. Copeia, 2005, 82-89.

Crampton, W.G.R., \& Albert, J.S. (2006). Evolution of electric signal diversity in gymnotiform fishes. In: Ladich, F., Collin, S.P., Moller, P. \& Kapoor, B.G (eds.). Communication in Fishes. Science Publishers Inc., Enfield, NH. pp. 641-725.

Eigenmann, C. H. (1908). Preliminary descriptions of new genera of tetragonopterid characins. Bulletin of the Museum of Comparative Zoology, 52, 94-106.

Fernandes, C.C., Podos, J., \& Lundberg, J.G. (2004). Amazonian Ecology: Tributaries Enhance the Diversity of Eletric Fishes. Science, 305, 1960-1962.

Fernandes-Matioli, F.M.de C. (1999). Evolução e estrutura de populações no gênero Gymnotus (Pisces: Gymnotiformes). Tese de Doutorado. Instituto de Biociências, Universidade de São Paulo, São Paulo. 165 p.

Fonteles, S.B.A, Fernandes, F.M.C, Lopes, C.A., \& Almeida-Toledo, L.F. (2005). Distribuição geográfica de Gymnotus pantherinus (Pisces: Gymnotiformes): uma revisão. Livro de Resumos do XVI Encontro Brasileiro de Ictiologia, p.199. 
Frankham, R., Ballou, J.D., \& Briscoe, D.A. (2008). Fundamentos de Genética da Conservação. Ribeirão Preto, SP: Editora SBG. 280 p.

Froese, R., \& Pauly, D. (2010) (Eds.) FishBase. World Wide Web electronic publication. www.fishbase.org, version (09/2010).

Gayet, M., \& Meunier, F.J. (1991). Première découverte de Gymnotiformes fossiles (Pisces, Ostariophysi) dans le Miocène supérieur de Bolivie. Comptes Rendus de l'Academie des Sciences Paris, 313, 471-476.

Gerhard, P., Moraes, R., \& Molander, S. (2004). Stream fish communities and their associations to habitat variables in a rain forest reserve in southeastern Brazil. Environmental Biology of Fishes, 71, 321-340.

Gonçalves, M. P. (2005). Revisão taxonômica do Complexo Gymnotus pantherinus (Steindachner, 1908) (Teleostei: Gymnotiformes). Dissertação de Mestrado, Museu Nacional, Universidade Federal do Rio de Janeiro, Rio de Janeiro. 90 p.

Gray, J.E. (1858). Synopsis of the families and genera of axiferous zoophytes or barked corals. Proceedings of the Zoological Society London, 25, 278-294.

Grazziotin, F.G., Monzel, M., Echeverrigaray, S., \& Bonatto, S.L. (2006). Phylogeography of the Bothrops jararaca complex (Serpentes: Viperidae): past fragmentation and island colonization in the Brazilian Atlantic Forest. Molecular Ecology, 15, 3969-3982.

Hubert, N., Duponchelle, F., Nuñez, J., Garcia-Davila, C., Paugy, D., \& Renno, J.F. (2007). Phylogeography of the piranha genera Serrasalmus and Pygocentrus: implications for the diversification of the Neotropical Ichthyofauna. Molecular Ecology, 16, 2115-2136.

Hubert, N., \& Renno, J. (2006). Historical biogeography of South American freshwater fishes. Journal of Biogeography. doi: 10.1111/j.1365-2699.2006.01518.x

Lissmann, H.W. (1958). On the function and evolution of electric organs in fish. Jounal of Experimental Biology, 35, 156-191.

Lovejoy, N.R., Lester, K., Crampton, W.G., Marques, F.P. \& Albert, J.S. (2010). Molecular Phylogenetics and Evolution Phylogeny, biogeography, and electric signal evolution of Neotropical knifefishes of the genus Gymnotus (Osteichthyes: Gymnotidae). Molecular Phylogenetics and Evolution, 54, 278-290.

Lundberg, J.G. (1993). African-South American freshwater fish clades and continetal drift: problems with a paradigm. In: Goldblatt, P. (Ed.) Biological Relationships Between Africa and South America. Yale University Press, New Haven. pp. 156-199.

Lundberg, J.G; Fernandes, C.C; Albert, J.S; Garcia, M. 1996. Magosternarchus, a new genus with two new species of electric fish (Gymnotiformes: Apteronotidae) from the Amazon River basin, South America. Copeia, 1996, 657-670.

Lundberg, J.G., Marshall, L.G., Guerrero, J., Horton, B., Malabarba, M.C.S.L., \& Wesselingh, F. (1998) The stage for Neotropical fish diversification: a history of tropical South American rivers. In: Malabarba, L.R., Reis, R.E., Vari, R.P., Lucena, Z.M., \& Lucena, C.A.S. (Eds) Phylogeny and Classification of Neotropical Fishes. Edipucrs, Porto Alegre. pp. 13-48. 
Mago-Leccia, F. (1994). Electric fishes of the continental waters of America. Biblioteca de la Academia de Ciencias Físicas, Matemáticas y Naturales, 29, Caracas, Venezuela. 1-225.

Maitland, P. (1995). The conservation of freshwater fish: Past and present experience. Biological Conservation, 72, 259-270.

Melo, C. E., Lima, J. D., \& Silva, E. F. (2009). Relationships between water transparency and abundance of Cynodontidae species in the Bananal floodplain, Mato Grosso, Brazil. Neotropical Ichthyology, 7(2), 251-256.

Menezes, N. A. (1996). Methods for assessing freshwater fish diversity. In: Bicudo, C.E.M. \& Menezes, N. A. (Eds.) Biodiversity in Brazil: a first approach. CNPq, Brasil.

Menezes, N.A, Weitzman, S.H, Oyakawa, O.T, Lima, F.C.T.de, Castro, R.M.C, \& Weitzman, M.J. (2007). Peixes de água doce da Mata Atlântica: lista preliminar das espécies e comentários sobre conservação de peixes de água doce neotropicais. São Paulo: Museu de Zoologia - Universidade de São Paulo. 408 p.

Menezes, N.A., Ribeiro, A.C., Weitzman, S. \& Torres, R.A. (2008). Biogeography of Glandulocaudinae (Teleostei: Characiformes: Characidae). Zootaxa, 1726, 33 - 48.

Milhomem, S. S., Pieczarka, J. C., Crampton, W. G., Silva, D. S., De Souza, A. C., Carvalho-Jr, J. R., \& Nagamachi, C. Y. (2008). Chromosomal evidence for a putative cryptic species in the Gymnotus carapo species-complex (Gymnotiformes, Gymnotidae), BMC Genetics, 9(75). http://dx.doi.org/10.1016/j.ympev.2009.09.017.

Montoya-Burgos, J.I. (2003). Historical biogeography of the catfish genus Hypostomus (Siluriformes: Loricariidae), with implications on the diversification of Neotropical ichthyofauna. Molecular Ecology, 12, 1855-1867.

Moritz, C., Patton, J.L., Schneider, C.J. \& Smith, T.B. (2000). Diversification of rainforest faunas: An integrated molecular approach. Annual Review of Ecology Systematics, 31, 533-563.

Moysés, C.B. (2005). Diversidade genética, estrutura populacional e análises filogenéticas no gênero Eigenmannia (Pisces: Gymnotiformes). Tese de Doutorado. Instituto de Biociências, Universidade de São Paulo, São Paulo. 220 p.

Myers, N., Mittermeier, R.A., Mittermeier, C.G., Fonseca, G.A. \& Kent, J. (2000). Biodiversity hotspots for conservation priorities. Nature, 403, 853-858.

Nagamachi, C.Y, Pieczarka, J.C., Milhomem, S.S.R., O'Brien, P.C.M., Souza, A.C.P., \& Ferguson-Smith, M.A. (2010). Multiple rearrangements in cryptic species of electric knifefish, Gymnotus carapo (Gymnotidae, Gymnotiformes) revealed by chromosome painting. BMC Genetics, 11(28). http://www.biomedcentral.com/1471-2156/11/28 .

Nelson, J.S. (2006). Fishes of the world. Order A Journal On The Theory Of Ordered Sets And Its Applications. 4 ed. New Jersey: John Wiley \& Sons.

Oyakawa, O.T, Akama, A, Mautari, K.C, \& Nolasco, J.C. (2006). Peixes de riachos da Mata Atlântica. São Paulo: Editora Neotrópica. 201 p. 
Pellegrino, K.C., Rodrigues, M.T., Waite, A.N., Morando, M., Yassuda, Y.Y. \& Sites-Jr, J.W. (2005). Phylogeography and species limits in the Gymnodactylus darwinii complex (Gekkonidae, Squamata): genetic structure coincides with river systems in the Brazilian Atlantic Forest. Biological Journal of the Linnean Society, 85, 13-26.

Potter, P. E. (1997). The Mesozoic and Cenozoic paleodrainage of South America: A natural history. Journal of South American Earth Sciences, 10(5-6): 331-344.

Reis, R.E., Kullander, S.O., Ferrari-Jr, C.J. (2003). Check list of the freshwater fishes of South and Central America. Porto Alegre: EDIPUCRS, 742 p.

Ribeiro, A. C. (2006). Tectonic history and the biogeography of the freshwater fishes from the coastal drainages of eastern Brazil : an example of faunal evolution associated with a divergent continental margin. Neotropical Ichthyology, 4(2), 225-246.

Riccomini, C. \& Assumpção, M. (1999). Quaternary tectonics in Brazil. Episodes, 22(3): 221225.

Rodrigues, M.T. (1987). Sistemática, ecologia e zoogeografia dos Tropidurus do grupo torquatus ao sul do rio Amazonas (Sauria, Iguanidae). Arquivos de Zoologia, 31, 105-230.

Rodrigues, M.T. (1990). Os lagartos da floresta Atlântica Brasileira: distribuição atual e pretérita e suas implicações para estudos futuros. II. Simpósio de ecossistemas da costa sul e sudeste Brasileira. Estutura, função e manejo. Academia de Ciências do Estado de São Paulo, $71,404-410$.

Rohr, D.M, \& Huddleston, R.W. (1982). Yochelsoniella, nom. nov., a new name for Ellisella Rohr, 1980 (Gastropoda) non Gray, 1858 (Coelenterata). Proceedings of the Biological Society of Washington, 95 (269).

Sarmento-Soares, L. M., \& Martins-Pinheiro, R. F. (2006). Rachoviscus graciliceps (Characidae: Incertae Sedis) sobrevivente nos pequenos riachos do extremo sul da Bahia, Brasil. Boletim da Sociedade Brasileira de Ictiologia, 4-5.

Shaffer, E.L. (1917). On the electric organs of Gymnotus carapo. Science, 45, 67-69.

Sivasundar, A., Bermingham, E. \& Orti, G. (2001). Population structure and biogeography of migratory freshwater fishes (Prochilodus: Characiformes) in major South American rivers. Molecular Ecology, 10, 407- 417.

Steindachner, F. (1908). Brachyplatystoma - Art aus dem Rio Parnahyba und über eine dicht gefleckte und gestrichelte varietät von Giton fasciatus aus dem Gewässern von Santos (Staat São Paulo). Anzeiger der Akademie der Wissenshaften, Wien, 45, 123-130.

Vanzolini, P.E., \& Williams, E.E. (1970). South American anoles: the geographic differentiation and evolution of the Anolis chrysolepis species group (Sauria: Iguanidae). Arquivos de Zoologia, 19, 1-298.

Vari, R. P. (1988). The Curimatidae, a lowland neotropical fish family (Pisces: Characiformes): distribution, endemism and phylogenetic biogeography. In: Vanzolini, P. E. \& Heyer, W. R. (Eds.) Proceedings of a Workshop on Neotropical Distribution Patterns. Academia Brasileira de Ciências, Rio de Janeiro, 488 p. 
Vari, R. P., \& Weitzman, S. H.. (1990). A review of the phylogenetic biogeography of the freshwater fishes of South America. Pp. 381-393. In: Peters, G. \& Hutterer, R. (Eds.). Vertebrates in the Tropics. Proceedings of the International Symposium on Vertebrate Biogeography and Systematics in the Tropics, Bonn, June 5-8, 1989. Alexander Koenig Zoological Research Institute and Zoological Museum, Bonn, 424p.

Weitzman, S.H., Menezes, N.A., Weitzman, M.J. (1988). Phylogenetic Biogeography of the Glandulocaudini (Teleostei: Characiformes, Caracidae) with comments on the distribuition of other freswater fishes in Eastern and Southeastern Brasil. Proceedings of a Workshop on Neotropical Distribuition Patterns, p.379-427.

\section{CAPÍtUULO II}

Albert, J.S. (2001). Species diversity and phylogenetic systematics of American knifefishes (Gymnotiformes, Teleostei). Misc. Publ. Mus. Zool. Univ. Mich. 190, 1-129.

Albert, J.S., \& Campos-da-Paz, R. (1998). Phylogenetic systematics of gymnotiformes with diagnoses of 58 clades: a review of available data. In: Malabarba, L.R., Reis, R.E., Vari, R.P., Lucena, Z.M., \& Lucena, C.A.S. (Eds.), Phylogeny and Classification of Neotropical Fishes. Edipucrs, Porto Alegre, pp. 419-443.

Albert, J.S., \& Crampton, W.G.R. (2001). Five new species of Gymnotus (Teleostei: Gymnotiformes) from an Upper Amazon floodplain, with descriptions of electric organ discharges and ecology. Ichthyological Exploration of Freshwaters, 12, 241- 266.

Albert, J.S., \& Crampton, W.G.R. (2003). Seven new species of the Neotropical electric fish Gymnotus (Teleostei, Gymnotiformes) with a redescription of G. carapo (Linnaeus). Zootaxa, $287,1-54$.

Albert, J.S., Fernandes-Matioli, F.M.D., \& Almeida-Toledo, L.F. (1999). New species of Gymnotus (Gymnotiformes, Teleostei) from southeastern Brazil: toward the deconstruction of Gymnotus carapo. Copeia, 1999, 410-421.

Altschul S.F., Gish W., Miller W., Myers E.W., \& Lipman D.J. (1990). Basic local alignment search tool. Journal of Molecular Biology, 215, 403-410.

Arévalo, E., Davis, S.K., \& Sites, J.W. (1994). Mitochondrial DNA sequence divergence and phylogenetic relationships among eight chromosome races of the Sceloporus grammicus complex (Phrynosomatidae) in Central Maxico. Systematic Biology, 43, 387-418.

Avise, J. C. (2000). Phylogeography: the history and formation of species. Harvard Univ. Press, Cambridge, MA. 447 p.

Ballard, J.W.O., \& Whitlock, M.C. (2004) The incomplete natural history of mitochondria. 
Molecular Ecology, 13, 729-744.

Birstein, V.J., Doukakis, P., Sorkin, B. \& Desalle, R. (1998) Population aggregation analysis of three caviar-producing species of sturgeons and implications for the species identification of black caviar. Conservation Biology, 12: 766-775.

Bremer, K. (1994) Branch support and tree stability. Cladistics, 10, 295-304.

Brown, W.M., George, M.Jr, \& Wilson, A.C. (1979). Rapid evolution of animal mitochondrial DNA. Proceedings of the National Academy of Sciences of the United States of America, 76,1967-1971.

Calcagnotto, D., Schaefer, S.A. \& Desalle, R. (2005) Relationships among characiform Wshes inferred from analysis of nuclear and mitochondrial gene sequences. Molecular Phylogenetics and Evolution, 36, 135-153.

Campos-da-Paz, R. (1997). Sistemática e taxonomia dos peixes elétricos das bacias dos rios Paraguai, Paraná e São Francisco, com notas sobre espécies presentes em rios costeiros do leste do Brasil (Teleostei: Ostariophysi: Gymnotiformes). Tese de Doutorado, Universidade de São Paulo, São Paulo, 336 p.

Campos-da-Paz, R. (2002). Gymnotus diamantinensis, a new species of electric knifefish from upper rio Arinos basin, Brazil (Ostariophysi: Gymnotidae). Ichthyological Exploration of Freshwaters, 13, 185-192.

Carvalho, G.R., \& Hauser, L. (1999). Molecular markers and the species concept: new techniques to resolve old disputes? Reviews in Fish Biology and Fisheries, 9, 379-382.

Chiachio, M.C., Oliveira, C. \& Montoya-Burgos, J.I. (2008). Molecular Phylogenetics and Evolution Molecular systematic and historical biogeography of the armored Neotropical catfishes Hypoptopomatinae and Neoplecostominae (Siluriformes: Loricariidae). Molecular Phylogenetics and Evolution, 49, 606-617.

Chow, S. \& Hazama, K. (1998). Universal PCR primers for S7 ribosomal protein gene introns in fish. Molecular Ecology, 7, 1255-1256.

Cracraft, J. (2000). Species Concepts in Theoretical and Applied Biology: A Systematic Debate with Consequences. In: Wheeler, Q.D., Meier, R. (Eds.) Species concepts and phylogenetic theory: a debate. New York: Columbia University Press, pp. 3-14.

Crampton, W.G.R., Lovejoy, N.R., \& Albert, J.S. (2003). Gymnotus ucamara: a new species of Neotropical electric fish from the Peruvian Amazon (Ostariophysi: Gymnotidae), with notes on ecology and electric organ discharges. Zootaxa, 277, 1-18.

Crampton, W.G.R., Thorsen, D.H., \& Albert, J.S. (2005). Three new species from a diverse and sympatric assemblage of the electric fish Gymnotus (Ostariophysi:Gymnotidae) in the lowland Amazon Basin, with notes on ecology. Copeia, 2005, 82-99.

Crespi, B.J. \& Fulton, M.J. (2004). Molecular systematics of Salmonidae : combined nuclear data yields a robust phylogeny. Molecular Phylogenetics and Evolution, 31, 658-679. 
Darwin, C. (1859). On the Origin of Species by Means of Natural Selection, or the Preservation of Favored Races in the Struggle for Life. London: John Murray, 502 p.

de la Torre, J. E., Egan, M. G., Katari, M. S., Brenner, E. D., Stevenson, D. W., Coruzzi, G. M., \& DeSalle, R. (2006). ESTimating plant phylogeny: lessons from partitioning. BMC Evolutionary Biology, 6(48). doi: 10.1186/1471-2148-6-48.

Doyle, J.J. (1992). Gene Trees and Species Trees: Molecular Systematics as One-Character Taxonomy. Systematic Botany, 17, 144-163.

Edgar, R.C. (2004) MUSCLE: multiple sequence alignment with high accuracy and high throughput. Nucleic Acids Research, 32(5), 1792-1797.

Edwards, S.V., \& Beerli, P. (2000). Gene divergence, population divergence, and the variance in coalescence time in phylogeographic studies. Evolution, 54(6): 1839-1854.

Ewing, B., \& Green, P. (1998). Base-calling of automated sequencer traces using phred. II. Error probabilities. Genome Research, 8(3), 186-194.

Ewing, B., Hillier, L., Wendl, M.C., \& Green, P. (1998). Base-calling of automated sequencer traces using phred. I. Accuracy assessment. Genome Research, 8(3), 175-185.

Fernandes, F. M., Albert, J. S., Daniel-Silva, M. F. Z., Lopes, C. E., Crampton, W. G., \& Almeida-Toledo, L. F. (2005). A new Gymnotus (Teleostei: Gymnotiformes: Gymnotidae) from the Pantanal Matogrossense of Brazil and adjacent drainages: continued documentation of a cryptic fauna. Zootaxa, 933, $1-14$.

Ferreira, ME \& Grattapaglia, D. (1996). Introdução ao uso de marcadores moleculares em análise genética. 2a. ed., Brasília, EMBRAPA-CENARGEN. 220 p.

Froese, R., \& D. Pauly. (Eds). (2010). FishBase. World Wide Web electronic publication. www.fishbase.org, version (07/2010).

Gatesy, J., O'Grady, P., \& Baker, R. H. (1999). Corroboration among Data Sets in Simultaneous Analysis: Hidden Support for Phylogenetic Relationships among Higher Level Artiodactyl Taxa. Cladistics, 15, 271-313. doi: 10.1111/j.1096-0031.1999. tb00268.x.

Giannasi, N., Malhotra, A. \& Thorpe, R.S. (2001). Nuclear and mtDNA Phylogenies of the Trimeresurus Complex: Implications for the Gene versus Species Tree Debate. Molecular Phylogenetics and Evolution, 19, 57- 66.

Goloboff, P. A., Farris, J. S., \& Nixon, K. C. (2008). TNT, a free program for phylogenetic analysis. Cladistics, 24, 774-786.

Gonçalves, M. P. (2005). Revisão taxonômica do Complexo Gymnotus pantherinus (Steindachner, 1908) (Teleostei; Gymnotiformes). Dissertação. UFRJ, Museu Nacional, Rio de Janeiro, $90 \mathrm{p}$.

Gordon, D., Abajian, C. \& Green, P. (1998). Consed: a graphical tool for sequence finishing. Genome Research, 8, 195-202.

Hall, T. A. (1999). BioEdit: a user-friendly biological sequence alignment editor and analysis 
program for Windows 95/98/NT. Nucleic Acids Symposium Series, 41, 95-98.

Harrison, R.G. (1989). Animal mitochondrial DNA as a genetic marker in population and evolutionary biology. Trends in Ecoogy and Evolution, 4, 6-11.

Hauser, L., Carvalho, G.R. \& Pitcher, T.J. (1998). Genetic similarity of a phenotypically divergent population of the clupeid Limnothrissa miodon following introduction into a manmade lake. In: Cowx, I.G. (ed.) Stocking and Introductions of Fish. Fishing News Books, Blackwell Scientific Ltd., Oxford, pp. 338- 354.

Hillis, D.M., Moritz, C., \& Mable, B.K. (1996). Molecular Systematics. 2a. ed. Sinauer Associates, Sunderland, MA. 655 p.

Holder, M., \& Lewis, P. O. (2003). Phylogeny estimation: traditional and Bayesian approaches. Nature reviews. Genetics, 4(4), 275-84. doi: 10.1038/nrg1044.

Hubert, N., \& Renno, J. (2006). Historical biogeography of South American freshwater fishes. Journal of Biogeography. doi: 10.1111/j.1365-2699.2006.01518.x.

Hubert, N., Duponchelle, F., Nunez, J., Garcia-Davila, C., Paugy, D. \& Renno, J. (2007). Phylogeography of the piranha genera Serrasalmus and Pygocentrus: implications for the diversification of the Neotropical ichthyofauna. Molecular Ecology, 16(10), 2115-36.

Huelsenbeck, J.P. \& Crandall, K.A. (1997). Phylogeny estimation and hypothesis testing using maximum likelihood. Annual Review of Systematic, 28, 437-466.

Kocher, T.D., Thomas, W.K., Meyer, A., Edwards, S.V., Pääbo, S., Villablanca, F.X. \& Wilson, A.C. (1989). Dynamics of mitochondrial DNA evolution in animals: amplification and sequencing with conserved primers. Proceedings of the National Academy of Sciences of the United States of America, 86(16), 6196-6200.

Lovejoy, N.R., Lester, K., Crampton, W.G., Marques, F.P. \& Albert, J.S. (2010). Molecular Phylogenetics and Evolution Phylogeny, biogeography, and electric signal evolution of Neotropical knifefishes of the genus Gymnotus (Osteichthyes: Gymnotidae). Molecular Phylogenetics and Evolution, 54, 278-290.

Maldonado-Ocampo, J.A., \& Albert, J.S. (2004). Gymnotus ardilai: a new species of Neotropical electric fish (Ostariophysi: Gymnotidae) from the Rio Magdalena of Colombia. Zootaxa, 759, 1-10.

Mayden, R. L. (1997). A hierarchy of species concepts: the denouement in the saga of the species problem. In: Claridge, M. A., Dawah, H. A., \& Wilson, M. R. (eds.). Species: The Units of Diversity. London: Chapman \& Hall. pp. 381-424.

Mayden, R.L., \& Wood, R.M. (1995). Systematics, species concepts and the evolutionary significant unit in biodiversity and conservation biology. American Fisheries Society Symposium, 17, 58-113.

Meier, R. (2008). DNA Sequences in Taxonomy: Opportunities and Challenges. In: Wheeler, Q. D. (Ed.) The New Taxonomy. Tempe, USA: CRC Press, pp.95-128.

Memon, N., Meier, R., Mannan, A. \& Su Feng-Yi, K. (2006). On the use of DNA sequences for 
determining the species limits of a polymorphic new species in the stink bug genus Halys (Heteroptera: Pentatomidae) from Pakistan. Systematic Entomology, 31, 703-710.

Menezes, N. A., Ribeiro, A. C., Weitzman, S., \& Torres, R. A. (2008). Biogeography of Glandulocaudinae ( Teleostei : Characiformes : Characidae ). Zootaxa, 1726, 33 - 48.

Milhomem, S.S., Pieczarka, J.C., Crampton, W.G., Silva, D.S., Souza, A.C., Carvalho-Jr, J.R. \& Nagamachi, C.Y. (2008). Chromosomal evidence for a putative cryptic species in the Gymnotus carapo species-complex (Gymnotiformes, Gymnotidae). BMC Genetics, 9, 1-10. doi:10.1186/1471-2156-9-75.

Moritz, C., Patton, J. L., Schneider, C. J., \& Smith, T. B. (2000). Diversification of rainforest faunas: An Integrated Molecular Approach. Annual Review of Ecology Systematics, 31, 533-563.

Nagamachi, C.Y., Pieczarka, J.C., Milhomem, S.S., O'Brien, P.C., de Souza, A.C. \& FergusonSmith, M.A. (2010). Multiple rearrangements in cryptic species of electric knifefish, Gymnotus carapo (Gymnotidae, Gymnotiformes) revealed by chromosome painting. BMC Genetics, 11. doi:10.1186/1471-2156-11-28.

Palumbi, S.R. (1996). Nuclei Acids II: The Polymerase Chain Reaction. In: Hillis, D.H., Moritz, C., \& Mable, B.K. (Eds.) Molecular Systematics. Sunderland, Massachusetts (USA): Sinauer Associates, Inc. 655 p.

Palumbi, S.R., \& Cipriano, F. (1998). Species identification using genetic tools: The value of nuclear and mitochondrial gene sequences in whale conservation. Journal of Heredity, 89, 459464.

Pank, M., Stanhope, M., Natanson, L., Kohler, N. \& Shivji, M. (2001). Rapid and simultaneous identification of body parts from the morphologically similar sharks Carcharhinus obscurus and Carcharhinus plumbeus (Carcharhinidae) using multplex PCR. Marine Biotechnology, 3, 231240.

Pereira, S.L., Baker, A.J. \& Wajntal, A. (2002). Combined nuclear and mitochondrial DNA sequences resolve generic relationship within the Cracidae (Galliformes, Aves). Systematics Biology, 51, 946-958.

Petersen, F.T., Meier, R., Kutty, S.N., \& Wiegmann, B.M. (2007). The phylogeny and evolution of host choice in the Hippoboscoidea (Diptera) as reconstructed using four molecular markers. Molecular Phylogenetics and Evolution, 45, 111-122.

Posada, D. \& Crandall, K. A. (1998). Modeltest: testing the model of DNA substitution. Bioinformatics, 14, 817-818.

Rambaut, A. \& Drummond, A.J. (2007). Tracer v.1.4, Available from http://beast.bio.ed.ac.uk/Tracer.

Ribeiro, A. C. (2006). Tectonic history and the biogeography of the freshwater fishes from the coastal drainages of eastern Brazil : an example of faunal evolution associated with a divergent continental margin. Neotropical Ichthyology, 4(2), 225-246.

Ribeiro, A.C, Lima, F.C.T., Riccomini, C., \& Menezes, N.A. (2006). Fishes of the Atlantic 
Rainforest of Boracéia: testimonies of the Quaternary fault reactivation within a Neoproterozoic tectonic province in Southeastern Brazil. Ichthyological Exploration of Freshwaters, 17(2), 157-164.

Richer-de-Forges, M.M., Crampton, W.G.R., \& Albert, J.S. (2009). A new species of Gymnotus (Gymnotiformes, Gymnotidae) from Uruguay: description of a model species in Neurophysiological Research. Copeia, 2009, 538-544.

Ronquist, F. \& Huelsenbeck, J.P. (2003). MrBayes v.3: Bayesian phylogenetic inference under mixed models. Bioinformatics, 19(12), 1572-1574.

Russo, C.A. (2001). Como escolher genes para problemas filogenéticos específicos? In: Matioli, S.R. (Ed.). Biologia Molecular e Evolução, Editora Holos, Ribeirão Preto-SP, pp.130-136.

Russo, C.A., Takezaki, N. \& Nei, M. (1996). Efficiencies of Different Genes and Different Tree-building in Recovering a Known Vertebrate Phylogeny. Molecular Biology and Evolution, 13, 525-536.

Schlötterer, C. (2004). The evolution of molecular markers-just a matter of fashion? Nature Reviews Genetics, 5(1), 63-69. doi: 10.1038/nrg1249.

Simmons, M. P., Pickett, K. M., \& Miya, M. (2004). How meaningful are Bayesian support values? Molecular Biology and Evolution, 21(1), 188-99. doi: 10.1093/molbev/msh014.

Slade, R.W., Moritz, C. \& Heideman, A. (1994). Multiple Nuclear-Gene Phylogenies: Application to Pinnipeds and Comparison with a Mitochondrial DNA Gene Phylogeny. Molecular Biology and Evolution, 11, 341-356.

Sunnucks, P. (2000). Efficient genetic markers for population biology. Trends in Ecology and Evolution, 15, 199-203.

Tamura, K., Dudley, J., Nei, M. \& Kumar, S. (2007). MEGA4: Molecular Evolutionary Genetics Analysis (MEGA) software version 4.0. Molecular Biology and Evolution, 24, 1596-1599.

Uieda, V. S. (1995). Comunidade de peixes de um riacho litorâneo: composição, habitat e hábitos. Tese de Doutorado. Universidade de São Paulo, São Paulo, 229 p.

Vogler, A. P., \& Desalle, R. (1994). Diagnosing Units of Conservation Management. Conservation Biology, 8(2), 354-363.

Ward, R. D., Hanner, R., \& Hebert, P. D. (2009). The campaign to DNA barcode all fishes, FISH-BOL. Journal of Fish Biology, 74, 329-356. doi: 10.1111/j.1095-8649. 2008.02080.x.

Wheeler, Q. D., \& Meier, R. (2000). Species concepts and phylogenetic theory: a debate. New York: Columbia University Press, $230 \mathrm{p}$. 


\section{CAPÍTULO III}

AB'Saber, N.A. (2003). Megamorfologia do território brasileiro. In: Cunha, S.B. \& Guerra, A.J.T. (Eds.) Geomorfologia do Brasil. Bertand Brasil, $3^{\text {a }}$. ed. Rio de Janeiro, pp.71-106.

Allendorf, F. W. \& Luikart, G. (2006). Conservation and the Genetics of Populations. WileyBlackwell, $664 \mathrm{p}$.

Avise, J. C. (2000). Phylogeography: the history and formation of species. Harvard Univ. Press, Cambridge, MA. 447 p.

Bandelt, H. J., Forster, P., \& Röhl, A. (1999). Median-joining networks for inferring intraspecific phylogenies. Molecular Biology and Evolution, 16, 37-48.

Beerli, P., \& Felsenstein, J. (2001). Maximum likelihood estimation of a migration matrix and effective population sized in $n$ subpopulations by using a coalescent approach. Proceedings of the National Academy of Sciences of the United States of America, 98, 4563-4568.

Beheregaray, L. B., Sunnucks, P., \& Briscoe, D. A. (2002). A rapid fish radiation associated with the last sea-level changes in southern Brazil: the silverside Odontesthes perugiae complex. Proceedings of the Royal Society Biological Sciences, 269(1486), 65-73. doi: 10.1098/rspb.2001.1838.

Beheregaray, L.B. (2008). Twenty years of phylogeography: the state of the field and the challenges for the Southern Hemisphere. Molecular Ecology, 17, 3754-3774.

Bernatchez, L., Guyomard, R. \& Bonhomme, F. (1992). DNA sequence variation of the mitochondrial control region among geographically and morphologically remote European brown trout Salmo trutto populations. Molecular Ecology, 1, 161-173.

Bremer, K. (1994) Branch support and tree stability. Cladistics, 10, 295-304.

Brower, A. V. Z. (1999). Delimitation of phylogenetic species with DNA sequences: a critique of Davis and Nixon's population aggregation analysis. Systematic Biology, 48, 199-231.

Brown, J. M., Abrahamson, W. G. \& Way, P. A. (1996). Mitochondrial DNA phylogeography of host races of the goldenrod ball gallmaker, Eurosta solidaginis (Diptera: Tephritidae). Evolution, 50, 777-786.

Burridge, C. P., Craw, D., \& Waters, J. M. (2006). River capture, range expansion, and cladogenesis: the genetic signature of freshwater vicariance. Evolution, 60(5), 1038-1049.

Burridge, C. P., Craw, D., \& Waters, J. M. (2007). An empirical test of freshwater vicariance via river capture. Molecular Ecology. doi:10.1111/j.1365-294X.2006. 03196.x.

Cardoso, Y. P., \& Montoya-Burgos, J. I. (2009). Unexpected diversity in the catfish Pseudancistrus brevispinis reveals dispersal routes in a Neotropical center of endemism: the Guyanas Region. Molecular Ecology, 18, 947-964. doi: 10.1111/j.1365-294X.2008.04068.x. 
Cobbold, P. R., Meisling, K.E., \& Mount, V. S. (2001). Reactivation of an obliquely rifted margin, Campos and Santos basins, southeastern Brazil. AAPG Bulletin, 85(11), 1925-1944.

Davis, J. L. \& Nixon, K. C. (1992). Population, genetic variation and the delimitation of phylogenetic species. Systematic Biology, 41, 421-435.

Depaulis, F., Mousset, S., \& Veuille, M. (2003). Power of neutrality tests to detect bottlenecks and hitchhiking. Journal of molecular evolution, 57 Suppl 1, S190-200. doi: 10.1007/s00239-003-0027-y.

Desalle, R., Templeton, A., Mori, I., Pletscher, S. \& Johnston, J. S. (1987). Temporal and spatial heterogeneity of mtDNA polymorphism in natural populations of Drosophila mercatorum. Genetics, 116(2), 15-223.

Echelle, A. A., \& Echelle, A. F. (1998). Evolutionary relationships of pupfishes in the Cyprinodon eximius complex (Atherinomorpha: Cyprinodontiformes). Copeia, 1998, 852-865.

Excoffier, L. (2001). Analysis of population subdivision. In: Balding, D.J., Bishop, M., \& Cannings, C. (Eds.). Handbook of Statistical Genetics. New York: John Wiley. pp. 271-307.

Excoffier, L., Smouse, P. \& Quattro, J. (1992). Analysis of molecular variance inferred from metric distances among DNA haplotypes: Application to human mitochondrial DNA restriction data. Genetics, 131, 479-491.

Excoffier, Laval, L. G. \& Schneider, S. (2005). Arlequin ver. 3.0: An integrated software package for population genetics data analysis. Evolutionary Bioinformatics Online, 1, 47-50.

$\mathrm{Fu}$, Y. (1996). New statistical tests of neutrality for DNA samples from a population. Genetics, 143(1), 557-570.

Fu, Y.-X. (1997). Statistical tests of neutrality of mutations against population growth, hitchhiking and backgroud selection. Genetics, 147, 915-925.

Fu, Y., \& Li, W. (1993). Statistical tests of neutrality of mutations. Genetics, 133, 693-709. Retrieved from http://www.pubmedcentral.nih.gov/articlerender.fcgi?artid=1208208\&tool= pmcentrez\& rendertype $=$ abstract.

Gollmann, G., Bouvet, Y., Karakousis, Y., \& Triantaphyllidis, C. (1997). Genetic variability in Chrondostoma from Austrian, French and Greek Rivers (Teleostei, Cyprinidae). Journal of Zoological Systematics and Evolutionary Research, 35, 165-169.

Goloboff, P. A., Farris, J. S., \& Nixon, K. C. (2008). TNT, a free program for phylogenetic analysis. Cladistics, 24, 774-786.

Goudet, J., Raymond, M., de-Meeüs, T. D., \& Rousset, F. (1996). Testing differentiation in diploid populations. Genetics, 144(4), 1933-1940.

Grant, W. S., \& Bowen, B. W. (1998). Shallow Population Histories in Deep Evolutionary Lineages of Marine Fishes: Insights From Sardines and Anchovies and Lessons for Conservation. Journal of Heredity, 89(5), 415-426.

Hedrick, P. W. (2005). Genetics of populations. 3rd ed. Jones and Bartlett, Boston, MA. 675 p. 
Hewitt, G. (2000). The genetic legacy of the Quaternary ice ages. Nature, 405, 907-913.

Hubert, N., \& Renno, J. F. (2006). Historical biogeography of South American freshwater fishes. Journal of Biogeography. doi:10.1111/j.1365-2699.2006.01518.x.N

Hurwood, D. A., \& Hughes, J. M. (1998). Phylogeography of the freshwater fish, Mogurnda adspersa, in streams of northeastern Queensland, Australia: evidence for altered drainage patterns. Molecular Ecology, 7, 1507-1517.

Kreiser, B. R., Mitton, J. B., \& Woodling, J. D. (2001). Phylogeography of the plains killifish, Fundulus zebrinus. Evolution, 55, 339-350.

Latta, R. G. (2008). Conservation genetics as applied evolution : from genetic pattern to evolutionary process. Evolutionary Applications, 1, 84-94.

Librado, P. \& Rozas, J. (2009). DnaSP v5: A software for comprehensive analysis of DNA polymorphism data. Bioinformatics, 25, 1451-1452.

Mayden, R. L. \& Matson, R. H. (1992). Systematics and biogeography of the Tennessee shiner, Notropis leuciodus (Cope) (Teleostei, Cyprinidae). Copeia, 1992, 954-968.

Meffe, G.K \& Vrijenhoek, R.C. (1998). Conservation genetic in the management of desert fishes. Conservation Biology, 2, 157-169.

Menezes, N.A, Weitzman, S.H, Oyakawa, O.T, Lima, F.C.T.de, Castro, R.M.C, \& Weitzman, M.J. (2007). Peixes de água doce da Mata Atlântica: lista preliminar das espécies e comentários sobre conservação de peixes de água doce neotropicais. São Paulo: Museu de Zoologia - Universidade de São Paulo. 408 p.

Moysés, C.B. (2005). Diversidade genética, estrutura populacional e análises filogenéticas no gênero Eigenmannia (Pisces: Gymnotiformes). Tese de Doutorado. Instituto de Biociências, Universidade de São Paulo, São Paulo. 220 p.

Myers, A.A. \& Giller, P.S. (1988). Analytical biogeography: an integrated approach to the study of animals and plant distributions. Chapman and Hall, London. pp. 578.

Near, T. J., Kassler, T. W., Koppelman, J. B., Dillman, C. B., \& Philipp, D. P. (2003). Speciation in north american black basses, Micropterus (Actinopterygii: Centrarchidae). Evolution, 57(7), 1610-1621.

Nei, M. (1987). Molecular Evolutionary Genetics. Columbia University Press, New York.

Nei, M. \& Kumar, S. (2000) Molecular Evolution and Phylogenetics. Oxford University Press, New York.

Neigel, J. (2002). Is F ST obsolete?. Conservation Genetics, 3, 167-173.

Nelson, G. \& Platnick, N. (1981). Systematics and biogeography: cladistics and vicariance. Columbia University Press, New York. pp.567.

Oyakawa, O.T, Akama, A, Mautari, K.C, \& Nolasco, J.C. (2006). Peixes de riachos da Mata Atlântica. São Paulo: Editora Neotrópica. 201 p. 
Ramos-Onsins, S.E. \& Rozas, J. (2002). Statistical Properties of New Neutrality Tests Against Population Growth. Molecular Biology and Evolution, 19, 2092-2100.

Raymond, M., \& Rousset, F. (1995). An exact test for population differentiation. Evolution, 49, 1280-1283.

Ribeiro, A. C. (2006). Tectonic history and the biogeography of the freshwater fishes from the coastal drainages of eastern Brazil : an example of faunal evolution associated with a divergent continental margin. Neotropical Ichthyology, 4(2), 225-246.

Ribeiro, A., Lima, F.C.T., Riccomini, C., \& Menezes, N.A. (2006). Fishes of the Atlantic Rainforest of Boracéia: testimonies of the Quaternary fault reactivation within a Neoproterozoic tectonic province in Southeastern Brazil. Ichthyological Exploration of Freshwaters, 17(2), 157-164.

Ruzzante, D. E., Walde, S. J., Gosse, J. C., Cussac, V. E., Habit, E., Zemlak, T. S., et al. (2008). Climate control on ancestral population dynamics: insight from patagonian fish phylogeography. Molecular Ecology. doi: 10.1111/j.1365-294X.2008.03738.x.

Ryder, O. A. (1986). Species Conservation and Systematics: the Dilemma of Subspecies. Trends in Ecoogy and Evolution, 1(1), 1-2.

Salzburger, W., Brandstätter, A., Gilles, A., Parson, W., Hempel, M., Sturmbauer, C., et al. (2003). Phylogeography of the vairone (Leuciscus souffia, Risso 1826) in Central Europe. Molecular Ecology, 12, 2371-2386. doi: 10.1046/j.1365-294X.2003.01911.x.

Sano, A., \& Tachida, H. (2005). Gene genealogy and properties of test statistics of neutrality under population growth. Genetics, 169(3), 1687-97. doi: 10.1534/ genetics. 104.032797.

Satta, Y. \& Takahata, N. (1990). Evolution of Drosophila mitochondrial DNA and the history of the melanogaster subgroup. Proceedings of the National Academy of Sciences of the United States of America, 87, 9558-9562.

Serra, J. P., Carvalho, F. R., \& Langeani, F. (2007). Ichthyofauna of the rio Itatinga in the Parque das Neblinas, Bertioga, São Paulo State: composition and biogeography. Biota Neotropica, 7(1), 81-86.

Simonsen, K. L., Churchill, G. A., \& Aquadro, C. F. (1995). Properties of statistical tests of neutrality for DNA polymorphism data. Genetics, 141(1), 413-429.

Sites-Jr, J. W., \& Marshall, J. C. (2003). Delimiting species: a Renaissance issue in systematic biology. Evolution, 18(9), 462-470. doi: 10.1016/S0169-5347(03)00184-8.

Smith, C.T., Nelson, R.J., Wood, C.C. \& Koop, B.F. (2001). Glacial biogeography of North American coho salmon (Oncorhynchus kisutch). Molecular Ecology, 10, 2775-2785.

Strange, R. M. (1998). MtDNA variation in Johnny darters (Pisces: Percidae) from eastern Kentucky supports stream capture for the origin of upper Cumberland River fishes. American Midland Naturalist, 140, 96-102.

Swofford, D.L. (2001). PAUP*. Phylogenetics Analysis Using Parsimony (* and Others 
Methods). Version 4.0b10. Sinauer Associates, Sunderland, Massachusetts.

Tajima, F. (1989). Statistical method for testing the neutral mutation hypothesis by DNA polymorphism. Genetics, 123, 585-595.

Templeton, A. R. (1998). Nested Clade Analysis of phylogeographic data: testing hypotheses about gene flow and population history. Molecular Ecology, 7, 381-397.

Villwock, J. A., \& Tomazelli, L. J. (1995). Geologia costeira do Rio Grande do Sul. Notas Técnicas, 8,1-45.

Vogler, A. P. \& Desalle, R. (1994). Diagnosing units of Conservation Management. Conservation Biology, 8(2), 534-563.

Vrijenhoek, R. C. (1998). Conservation genetics of freshwater fish. Journal of Fish Biology, 53(Supplement A), 394-412.

Ward, R.D., Woodwark, M. \& Skibinski, D.O.F. (1994). A comparison of genetic diversity levels in marine, freshwater and anadromous fishes. Journal of Fish Biology, 44, 213-232.

Waters, J. M., Craw, D., Youngson, J. H., \& Wallis, G. P. (2001). Genes Meet Geology: Fish Phylogeographic Pattern Reflects Ancient, Rather than Modern, Drainage Connections. Evolution, 55(9), 1844-1851.

Waters, J. M., Lintermans, M., \& White, R. W. G. (1994). Mitochondrial DNA variation suggests river capture as a source of vicariance in Gadopsis bispinosus (Pisces: Gadopsidae). Journal of Fish Biology, 44, 549-551.

Weitzman, S.H., Menezes, N.A., Weitzman, M.J. (1988). Phylogenetic Biogeography of the Glandulocaudini (Teleostei: Characiformes, Caracidae) with comments on the distribuition of other freswater fishes in Eastern and Southeastern Brasil. Proceedings of a Workshop on Neotropical Distribuition Patterns, p.379-427.

Whitlock, M. C., \& Mccauley, D. E. (1999). Indirect measures of gene flow and migration: FST $\neq 1 /(4 \mathrm{Nm}+1)$. Heredity, $82,117-125$. 